University of Wollongong

Research Online

Faculty of Engineering and Information

Faculty of Engineering and Information

Sciences - Papers: Part B

Sciences

2018

\title{
Numerical Simulation of the Shear Behavior of Rock Joints Filled with Unsaturated Soil
}

Libin Gong

University of Wollongong, lg283@uowmail.edu.au

Jan Nemcik

University of Wollongong, jnemcik@uow.edu.au

Ting X. Ren

University of Wollongong, tren@uow.edu.au

Follow this and additional works at: https://ro.uow.edu.au/eispapers1

Part of the Engineering Commons, and the Science and Technology Studies Commons

Research Online is the open access institutional repository for the University of Wollongong. For further information contact the UOW Library: research-pubs@uow.edu.au 


\title{
Numerical Simulation of the Shear Behavior of Rock Joints Filled with Unsaturated Soil
}

\author{
Abstract \\ Weak infilled discontinuities commonly exist in rock masses, in which the infill degree of saturation \\ largely influences the overalljoint shear behavior and ground stability. However, so far, research on the \\ shear of infilled joints at unsaturated conditions is rare, especiallythose performed in numerical \\ simulation. To the authors'knowledge, no attempts have been made to investigate the shear-induced \\ variationsin unsaturated soil parameters, which are vital for proposing the infilled-joint constitutive \\ models. For thefirst time, a series of constant watercontent direct shear tests on the unsaturated infilled- \\ joint soil were conducted using the numerical software Fast Lagrangian Analysis ofContinua (FLAC)/Two- \\ Phase Flow. Intrinsic soil-water retention and permeability models were updated in the FISH subroutine to \\ considerporosity. Results highlight the disadvantage of the built-in models in FLAC. Initial infill saturation \\ and other factors, including physical shearrate, joint roughness, infill thickness, and normal stress, all \\ showed effects on the joint shear strength consistent with literature reports. Shear-induced variations in \\ the mean values of Bishop effective stress and permeability of the infill layer were emphasized

\section{Disciplines} \\ Engineering | Science and Technology Studies

\section{Publication Details} \\ Gong, L., Nemcik, J. \& Ren, T. (2018). Numerical Simulation of the Shear Behavior of Rock Joints Filled \\ with Unsaturated Soil. International Journal Of Geomechanics, 18 (9), 04018112-1-04018112-16.
}




\title{
Numerical Simulation of the Shear Behaviour of Rock Joints Filled with
}

\section{Unsaturated Soil}

\author{
Libin Gong ${ }^{1}$, Jan Nemcik ${ }^{2}$, and Ting Ren ${ }^{3}$ \\ ${ }^{1} \mathrm{PhD}$ Candidate, School of Civil, Mining and Environmental Engineering, University of Wollongong, NSW 2500, \\ Australia (corresponding author). Email: lg283@uowmail.edu.au \\ ${ }^{2}$ Honorary Senior Fellow, School of Civil, Mining and Environmental Engineering, University of Wollongong, NSW \\ 2500, Australia. Email: jnemcik@uow.edu.au \\ ${ }^{3}$ Associate Professor, School of Civil, Mining and Environmental Engineering, University of Wollongong, NSW 2500, \\ Australia. Email: tren@uow.edu.au
}

Abstract: Weak infilled discontinuities commonly exist in rock masses, where the infill degree of saturation largely influences the overall joint shear behaviour and ground stability. However so far, researches on the shear of infilled joints at unsaturated conditions are rare, especially those carried out in numerical simulation. Also to the authors' knowledge, no attempts have been made to investigate the shear-induced variations in unsaturated soil parameters that are vital for proposing the infilled-joint constitutive models. For the first time, a series of constant water content direct shear tests on the unsaturated infilled-joint soil were conducted using the numerical software FLAC/Two-Phase Flow. Intrinsic soil-water retention and permeability models were updated in FISH subroutine to consider porosity. Results highlight the disadvantage of the built-in models in FLAC. Initial infill saturation and other factors including physical shear rate, joint roughness, infill thickness and normal stress all showed effects on the joint shear strength consistent with literature reports. Shear-induced variations in the mean values of Bishop effective stress and permeability of the infill layer were emphasised.

Author keywords: Infilled rock joints, porosity, FLAC, two-phase flow, unsaturated soil, degree of saturation, matric suction, ground stability. 


\section{Introduction}

Rock discontinuities filled with soil-like materials commonly exist in rock masses, such as clayinfilled joints, faults and shear zones, weak bedding planes and dykes etc. (Brady and Brown 2013). These discontinuities largely weaken the overall stability of rock masses (Barton 1974), which is one of the largest concerns in mining and civil engineering. Factors dominating the joint shear behaviour have been investigated for decades (Phien-wej et al. 1990; de Toledo and de Freitas 1993; Indraratna et al. 2001, 2010), however the influence of infill saturation/water condition has not been recognised until recently (Alonso et al. 2013; Indraratna et al. 2014; Khosravi et al. 2016). In fact the joint infill can be either saturated or unsaturated depending on the liquid/gas flow conditions (Barton 1974; Matray et al. 2007; Alonso et al. 2013). Particularly in mining engineering, either open cut or shallow underground where the excavations are located above the water table, the infilled joints located in rock strata may be unsaturated in most of the times and mainly influenced by climate changes. Even in mining excavations located deep below the water table, the infilled joints can be unsaturated: mining activities enhance the permeability in the vicinity of the excavation, causing drainage of the distributed infilled joints, while ventilation and geothermal conditions also increase the desaturation. Fig. 1 illustrates typical situations in mining engineering where the unsaturated conditions may exist.

Compared with fully saturated condition, the shear strength of infilled joints would become higher when the infill material dries (i.e. has a lower degree of saturation), due to the contribution of matric suction strength. On the other hand, heavy precipitation or groundwater inrush may saturate the infill joints from initial dry (unsaturated) condition. This would dramatically decrease the shear strength and catastrophes may occur if insufficient reinforcement is applied. Hence it is 
of great importance to investigate the influence of infill saturation condition on the overall joint shear behaviour to ensure safety or minimise cost in support design.

During shear of rough joints filled with unsaturated materials, the stress state variables controlling the shear behaviour, such as matric suction of the infill, would vary with shear displacement. The variation may be minor for pure soil shear tests under homogenous loading (Tarantino and Tombolato 2005), whereas this may not prevail for infilled rough joints. During joint shear, the infill would suffer from not only highly concentrated stress in the area where joint asperities come into contact, but also possible unloading of certain joint areas caused by the volumetric separation (Fig. 2). In addition, the soil-water retention curve (SWRC) and permeability of the infill will change during shear with its porosity (Mašín 2010; Gallipoli et al. 2015; Hashem 2016; Carrier and Beckman 1984). All these factors may cause large variation of suction and saturation values in the shear process under hydraulic-mechanical coupling.

Understanding the shear-induced variations of these unsaturated soil parameters is vital for predicting the shear strength or stress-strain curves for infilled joints shear. This is especially important in mining disturbed strata where intermittent shear frequently occurs on located infilled joints during and after excavation. Shear stress of these joints may vary significantly due to deformation-induced changes of those parameters, which could largely influence the factor of safety in the rock reinforcement design. However study considering the shear-induced variations of those parameters is very rare in literature. Khosravi et al. (2016) investigated the effect of hydraulic hysteresis and saturation degree of the infill material on the joint shear strength in laboratory under matric suction-controlled condition. Yet such condition eliminates the supposed variation of infill matric suction during shear. Indraratna et al. (2014) conducted joint shear tests with unsaturated infills under Constant Water content $(\mathrm{CW})$ condition and keep the pore air 
pressure atmospheric. This condition is more realistic compared with suction-controlled case, but the variations of suction and degree of saturation during shear were not studied. This was largely because of the measurement difficulty due to harsh environment in the sheared infill and possible inhomogeneous suction distribution (depending on the permeability and shear rate parameters). In their study, it was the initial infill suction and saturation values before shear that were directly substituted into the conventional unsaturated soil shear strength model (Vanapalli et al. 1996), for predicting the joint shear strength. The changes of those parameters in shearing were neglected.

Due to the highly inhomogeneous distribution of both mechanical and hydraulic parameters inside the rough joint infill under shear, and the difficulties in measuring those parameters in the laboratory, numerical simulation becomes a much more feasible way of investigating their changes and the overall shear behaviour. In other words, it is ideal to trace or "measure" any variables in numerical models. However to date, numerical modelling of the infilled rough joints shear behaviour has been rare again. Chiu et al. (2016) and Ma et al. (2017) simulated the shear behaviour of clean rock joints using the distinct element method (DEM) or discontinuous deformation analysis (DDA). Yu and Bathurst (2017), Yu et al. (2015) and Wu et al. (2015) simulated the interaction between soil and geosynthetic materials, concrete structure or rock. $\mathrm{Lu}$ et al. (2017) and Duriez et al. (2011) simulated the behaviour of rock joints filled with either strong cement or normal gouge material. In all those models the impact of the soil/infill saturation degree was not considered.

In fact, for simulating pure unsaturated soil behaviour, various computer programs have been established, such as SVFlux, VADOSE/W, RestrasoCodeBright, PLAXIS/PlaxFlow and Fast Lagrangian Analysis of Continua (FLAC)/Two-Phase Flow etc. (Thode and Fredlund 2009; GEOSLOPE International 2014; Saaltink et al. 2005; Itasca Consulting Group 2011). Among those 
programs, the finite difference code FLAC is much more flexible as it contains primary engineering support elements which can be employed directly. Futhermore, it has a built-in scripting language FISH, and the explicit solution scheme is used in the two-phase flow mode. This enables the user to easily modify the internal parameters and functions at any intended interval. Recently the FLAC/Two-Phase Flow has been adopted by some researchers to investigate the behaviour of unsaturated soil (Davies et al. 2014; Cho 2016).

This paper employed the preceding FLAC/Two-Phase Flow to study the shear behaviour of rock joints filled with unsaturated soil materials, and especially the variation trends of those fundamental parameters. Fully mated laboratory infilled joint specimens were modelled, representing the tensile-opening joints filled with transported materials before shear movement. Tests were run under Constant Normal Load (CNL) and CW conditions. For simplicity, a small shear displacement was applied to prevent joint asperities contact, and only the "first stage" shear behaviour of infilled joints was investigated. Unsaturated flow and volumetric deformation of the infill material were coupled within the framework of quasi-static Biot theory. As the embedded governing equations in FLAC do not consider the influence of porosity on the SWRC and permeability, those equations were modified through FISH subroutine to be porosity-related and thus reflected the infill behaviour more accurately. The variation trends of basic hydraulic and mechanical properties of the infill material e.g. permeability, effective normal stress, shear stress/strength and normal displacement were investigated under different conditions. These involved varying levels of infill porosity-update times, initial infill degree of saturation, physical shear rate, joint roughness coefficient (JRC), ratio of infill thickness to joint asperity height ( $t / a$ ratio), and applied normal stress. Also the general influence of these factors on the shear behaviour was analysed qualitatively and some of them were compared with previous literature reports. 


\section{Problem Statement}

This study modelled the 2D direct shear tests of infilled rock joints in a laboratory scale using the FLAC/Two-Phase Flow, for the purpose to investigate the shear behaviour of unsaturated infill joints essential in ground stability assessment. Simulated upper and lower rock parts of the joint were $20 \mathrm{~mm}$ high and $100 \mathrm{~mm}$ wide, respectively, representing the fully saturated high-strength gypsum (Hydrostone) plaster commonly used in laboratory rock joint tests. The infill material between the upper and lower joint surfaces represents the Speswhite kaolin, with a height ranging from $1.47 \mathrm{~mm}$ to $5.91 \mathrm{~mm}$, depending on the desired $t / a$ ratio. Apart from a series of planar joints, two more levels of joint roughness were chosen based on the Barton's standard profiles (Fig. 3). As shown in Table 1, totally 17 tests were modelled, investigating the influences of porosity-update times, applied shear velocity, degree of infill saturation, physical shear rate, JRC, t/a ratio and normal stress. Details of each parameter were explained and presented in the section "Parametric Study".

\section{Theoretical Framework}

\section{Fluid transport}

During joint shear, both water and air will transfer inside the infill layer. Water and air transport in FLAC are described by Darcy's law:

$$
\begin{gathered}
Q_{\mathrm{w}}=\kappa_{\mathrm{r}}^{\mathrm{w}}\left[M_{\mathrm{w}}\right]\left(u_{\mathrm{w}}-\rho_{\mathrm{w}} g_{i} x_{i}\right) \\
Q_{\mathrm{g}}=\kappa_{\mathrm{r}}^{\mathrm{g}} \frac{\mu_{\mathrm{w}}}{\mu_{\mathrm{g}}}\left[M_{\mathrm{w}}\right]\left(u_{\mathrm{g}}-\rho_{\mathrm{g}} g_{i} x_{i}\right)
\end{gathered}
$$

where $Q_{\mathrm{w}}$ and $Q_{\mathrm{g}}$ are the nodal volumetric flow rates in a model zone in FLAC, $\kappa_{\mathrm{r}}^{\mathrm{w}}$ and $\kappa_{\mathrm{r}}^{\mathrm{g}}$ are relative permeabilities for the zone, $\mu_{\mathrm{w}}$ and $\mu_{\mathrm{g}}$ are dynamic viscosities, $u_{\mathrm{w}}$ and $u_{\mathrm{g}}$ are pore pressures, $\rho_{\mathrm{w}}$ and $\rho_{\mathrm{g}}$ are fluid densities, $\mathrm{g}_{i}, x_{i}, i=1,2$ are the two components of the gravity vector and coordinate vector respectively, and $\left[M_{\mathrm{w}}\right]$ is the "stiffness" matrix of the model zone 
representing the saturated mobility coefficients. The superscripts or subscripts g and $\mathrm{w}$ represent gas/air and water, respectively.

The calculation of relative permeabilities mentioned above for water and air follow the empirical laws of the van Genuchten form imbedded in FLAC:

$$
\begin{gathered}
\kappa_{\mathrm{r}}^{\mathrm{w}}=S_{\mathrm{e}}^{b}\left[1-\left(1-S_{\mathrm{e}}^{1 / a}\right)^{a}\right]^{2} \\
\kappa_{\mathrm{r}}^{\mathrm{g}}=\left(1-S_{\mathrm{e}}\right)^{c}\left[\left(1-S_{\mathrm{e}}^{1 / a}\right]^{2 a}\right. \\
S_{\mathrm{e}}=\frac{S_{\mathrm{r}}-S_{\mathrm{res}}}{1-S_{\mathrm{res}}}
\end{gathered}
$$

where $a, b$ and $c$ are constant parameters; $S_{\mathrm{r}}$ is the degree of saturation, $S_{\mathrm{e}}$ is the effective degree of saturation, and $S_{\text {res }}$ is the residual degree of saturation, all in terms of water.

\section{SWRC model}

The SWRC model describing the relationship between infill matric suction and degree of saturation in FLAC also follows the van Genuchten form:

$$
\begin{gathered}
s=P_{0}\left[S_{\mathrm{e}}^{-1 / a}-1\right]^{1-a} \\
s=u_{\mathrm{g}}-u_{\mathrm{w}}
\end{gathered}
$$

where $P_{0}$ is a parameter relating to surface tension, intrinsic permeability and porosity of the material, and $s$ is matric suction of the porous material.

\section{Porosity corrected SWRC and permeability}

As mentioned in Section 1, both the SWRC and permeability are dependent on porosity of the infill material. However FLAC simply adopts the retention model of the van Genuchten form (Eq. 6) which is independent on the porosity. And the saturated mobility coefficient involved in Eq. (12) is just an input parameter irrelevant to porosity. Also FLAC does not update porosity during solving due to time-consuming calculations. In this study the porosity of the material was updated 
first using the FISH subroutine, based on Mohr-Colum elastic-plastic model. Then the SWRC model and the saturated mobility coefficient were modified by FISH to consider the influence of porosity.

\section{Porosity}

Before yielding, the Mohr-Coulomb model is elastic following Hooke's law. Elastic volumetric strain $e^{\mathrm{e}}$ can be calculated by:

$$
e^{\mathrm{e}}=\frac{\sigma_{1}+\sigma_{3}}{\alpha_{1}+\alpha_{2}}
$$

where $\sigma_{1}$ and $\sigma_{3}$ are the major and minor principal stresses, respectively; $\alpha_{1}=K+4 G / 3$ and $\alpha_{2}=K-2 G / 3$, where $K$ is drained bulk modulus and $G$ is shear modulus.

As large strain mode is applied in the model, the volumetric strain is better approximated by

$$
e_{\text {large }}^{\mathrm{e}}=\frac{2 e^{\mathrm{e}}}{2+e^{\mathrm{e}}}
$$

As the FISH-subroutine access to principal stresses is not provided in FLAC, they were converted from the stress components in a Cartesian coordinate frame available within FISH:

$$
\begin{aligned}
& \sigma_{1}=\frac{\sigma_{x x}+\sigma_{y y}}{2}+\frac{1}{2} \sqrt{\left(\sigma_{x x}-\sigma_{y y}\right)^{2}+4\left(\sigma_{x y}\right)^{2}} \\
& \sigma_{3}=\frac{\sigma_{x x}+\sigma_{y y}}{2}-\frac{1}{2} \sqrt{\left(\sigma_{x x}-\sigma_{y y}\right)^{2}+4\left(\sigma_{x y}\right)^{2}}
\end{aligned}
$$

where $\sigma_{x x}, \sigma_{y y}$ and $\sigma_{x y}$ are three components of stress tensor.

The FISH-specific model variable e_plastic was used to detect if plastic flow occurs or not. This variable represents accumulated plastic volumetric strain relating to the shear yield surface. If $e_{-}$plastic $=0$, the material is still elastic; otherwise it is yielded and the total volumetric strain $e_{\mathrm{v}}$ is

$$
e_{\mathrm{v}}=e_{\text {large }}^{\mathrm{e}}+e_{-} \text {plastic }
$$


In the large strain mode in FLAC (set in current study), porosity $n$ can then be approximated as

$$
n=1-\frac{2-e_{\mathrm{v}}}{2+e_{\mathrm{v}}}\left(1-n_{0}\right)
$$

where $n_{0}$ is the initial porosity.

Porosity-corrected SWRC

To consider porosity in Eq. (6), define:

$$
\begin{gathered}
S_{\text {res }}=0 \\
P_{0}=\frac{(1-n)^{\psi}}{\varphi \cdot n^{\psi}}
\end{gathered}
$$

where $\varphi, \psi$ are constant parameters.

Equation (6) is then transformed to

$$
S=\frac{(1-n)^{\psi}}{\varphi \cdot n^{\psi}}\left[S_{\mathrm{r}}^{-1 / a}-1\right]^{1-a}
$$

which is exactly the form of the SWRC model proposed by Gallipoli et al. (2003):

$$
S_{\mathrm{r}}=\left[\frac{1}{1+\left(\varphi e^{\psi}\right)^{1 /(1-a)}}\right]^{a}
$$

where $e$ is void ratio defined as

$$
e=\frac{n}{1-n}
$$

In this way, the relationship between degree of saturation and matric suction is capable of varying with the change of porosity during calculation cycles.

\section{Porosity-corrected permeability}

As mentioned before, FLAC requires saturated mobility coefficient $k$ (in $\mathrm{m}^{2} /(\mathrm{Pa} \cdot \mathrm{s})$ ) in the "stiffness" matrix $\left[M_{\mathrm{w}}\right]$, which can be converted from conventional saturated hydraulic conductivity $k_{\text {sat: }}$ 


$$
k=\frac{k_{\mathrm{sat}}}{g \rho_{\mathrm{w}}}
$$

where $g$ is the gravitational acceleration.

For remolded clays, Carrier III and Beckman (1984) showed that

$$
k_{\mathrm{sat}} \approx \frac{0.0174}{1+e}\left\{\frac{e-0.027(P L-0.242 P I)}{P I}\right\}^{4.29}
$$

where $P I$ is plastic index for the material, $P L$ is plastic limit for the material.

This empirical model was employed here to correct the saturated mobility coefficient $k$ of the Speswhite kaolin infill for porosity:

$$
k \approx \frac{0.0174(1-n)}{g \rho_{\mathrm{w}}}\left\{\frac{n-0.027(P L-0.242 P I)(1-n)}{(1-n) P I}\right\}^{4.29}
$$

\section{Fluid-mechanical coupling}

Typically there are two ways of fluid-mechanical coupling during joint shear. Saturation/suction changes induce volumetric deformation of the material, while deformation will result in saturation/suction changes at the same time.

\section{Saturation/suction changes induced deformation}

In FLAC, the presence of fluid will increase mechanical stiffness of the porous medium, based on the quasi-static Biot theory:

$$
K^{\prime}=K+\frac{S_{\mathrm{r}} K_{\mathrm{w}}+\left(1-S_{\mathrm{r}}\right) K_{\mathrm{g}}}{n}
$$

where $K^{\prime}$ is apparent bulk modulus, $K$ is drained bulk modulus of the medium, $K_{\mathrm{w}}$ and $K_{\mathrm{g}}$ are fluid bulk moduli, and $n$ is porosity. Since bulk modulus of the air phase is several orders lower than $K$ and $K_{\mathrm{w}}$ which can be neglected, $K^{\prime}$ were then estimated by

$$
K^{\prime}=K+\frac{S_{\mathrm{r}} K_{\mathrm{w}}}{n}
$$

Also in FLAC, the Bishop effective stress, or average skeleton stress, is used to describe the stress state of an unsaturated material. It is defined as: 


$$
\sigma_{i j}^{\prime}=\sigma_{i j}-\delta_{i j} u_{\mathrm{g}}+\delta_{i j} S_{\mathrm{r}} S
$$

where $\sigma_{i j}^{\prime}$ is effective stress, $\sigma_{i j}$ is the total stress, and $\delta_{i j}$ is Kronecker delta.

Therefore, the increments in degree of saturation and matric suction will cause changes in both mechanical stiffness and effective stress, and then volumetric deformation.

\section{Deformation induced saturation/suction changes}

In transient two-phase flow-mechanical calculations, volume changes induce matric suction and saturation variations within the framework of the quasi-static Biot theory:

$$
\begin{gathered}
\Delta u_{\mathrm{w}}=-\frac{\Delta t}{n V D}\left[Q_{\mathrm{w}}\left(1-\frac{\left(1-S_{\mathrm{r}}\right) s^{\prime}}{K_{\mathrm{g}}}\right)+Q_{\mathrm{g}}\right]-\beta \frac{\Delta V}{n V D}\left[1-S_{\mathrm{r}} \frac{\left(1-S_{\mathrm{r}}\right) s^{\prime}}{K_{\mathrm{g}}}\right] \\
\Delta S_{\mathrm{r}}=-\frac{\Delta t}{n V D}\left[Q_{\mathrm{w}} \frac{1-S_{\mathrm{r}}}{K_{\mathrm{g}}}-Q_{\mathrm{g}} \frac{S_{\mathrm{r}}}{K_{\mathrm{w}}}\right]-\beta \frac{\Delta V}{n V D} S_{\mathrm{r}}\left(1-S_{\mathrm{r}}\right)\left[\frac{1}{K_{\mathrm{g}}}-\frac{1}{K_{\mathrm{w}}}\right]
\end{gathered}
$$

where $D$ is defined as

$$
D=\frac{S_{\mathrm{r}}}{K_{\mathrm{w}}}+\frac{1-S_{\mathrm{r}}}{K_{\mathrm{g}}}-\frac{S_{\mathrm{r}}}{K_{\mathrm{w}}} \frac{\left(1-S_{\mathrm{r}}\right) s^{\prime}}{K_{\mathrm{g}}}
$$

$\Delta u_{\mathrm{w}}$ and $\Delta S_{\mathrm{r}}$ are the incremental pore water pressure and degree of saturation in terms of water respectively, $\Delta t$ is the stable timestep in two-phase flow calculation, $V$ is nodal volume, $\mathrm{s}^{\prime}$ is differentiation of equation (6) with respect to $S_{\mathrm{r}}, \beta$ is undrained coefficient, and $\Delta V$ is volume change.

Fig. 4 shows the basic hydro-mechanical coupling scheme in FLAC explicit calculation. During cycling, changes in effective stress and mechanical stiffness cause volumetric deformation, governed by Mohr-Coulomb model, which leads to the changes in degree of saturation and matric suction following Eq. (25-26). Effective stress is then updated by the new saturation-weighted suction increments (Eq. 24). On the other hand, volumetric strain induces changes in porosity, which corrects the SWRC parameters and permeability, as shown in Eq. (16) and Eq. (21) respectively. Such corrections also influence Eq. (25-26), apart from the effect of volume change. 
Besides, varying porosity updates the apparent mechanical stiffness as well (Eq. 23). These porosity dependencies are accounted for in the FISH subroutine under a specific updating frequency, as described detailedly in the section "parametric study - porosity correction".

\section{Modelling Procedures}

\section{Grid generation}

An initial grid of $153 \times 30$ zones was set up, representing a rock joint shear model in a laboratory scale of $100 \mathrm{~mm}$ wide, and the upper and lower rock parts are $20 \mathrm{~mm}$ high, respectively. Note that the total number of grid zones and the height of the model will vary with the simulated joint roughness and infill thickness. Models with three levels of joint roughness (planar, JRC $=8-10$, $\mathrm{JRC}=18-20)$ and three levels of $t / a$ ratio $(0.5,1.0,1.5)$ were first established. Note that the asperity heights of the two rough profiles were calculated following the ISRM recommendations (ISRM 1981), with $2.94 \mathrm{~mm}$ for JRC=8-10, and $3.94 \mathrm{~mm}$ for JRC=18-20, respectively. To generate rough joint profiles in the model, the surfaces were initially replicated from Barton's standard profiles (Fig. 3) in AUTOCAD software using spline with constant segments between control points. The splines were then converted to tables with $x$-y coordinates of each control point. The shape of the joint can be generated afterwards combining the Table command in FLAC. Model geometries with different JRCs and $t / a$ ratios are shown in Fig. 5.

\section{Boundary and initial conditions}

As mentioned, a constant vertical stress was applied on top of the infilled joint model to simulate CNL conditions in laboratory direct shear tests. Initially, both sides of the upper block and left side of the lower block were fixed in x-direction; bottom boundary was fixed in y-direction. The boundaries of the infill material were impermeable to water. Pore air pressure was fixed as 
atmospheric in the system. After initial equilibrium, a horizontal velocity was applied to the lower block to produce a shear displacement (shear direction as shown in Fig. 6).

\section{Choice of constitutive model and solid/fluid properties}

\section{Models and properties for rock and soil}

As the objective of this study is the behaviour of unsaturated infill confined by rough joint surfaces, the upper and lower rock parts were simply set by isotropic elastic model. Elastic parameters for saturated hydrostone (high strength gypsum) were adopted. The Speswhite kaolin infill was modelled as a Mohr-Coulomb (M-C) material. Note that the M-C model was replaced by the strainharding/softening (S-S) model in the code, for getting easy access to the FISH variable $e$ plastic. However the cohesion, friction, dilation and tensile strength all remained constant, thus the S-S model was degraded to the intended M-C model. Typical properties of the soil were summarised in Table 2. Deformability and strength properties required in FLAC for both the rock part and the infill part were listed in Table 3. Drained strength parameters were used here, as the yield criterion adopted is expressed in terms of effective stresses as described in Eq. (10). Also, drained bulk modulus rather than undrained bulk modulus was used, and the apparent bulk modulus of the medium was modified in the FLAC logic following Eq. (9). Permeability, water retention parameters and fluid properties are listed in Table 4. As the SWRC model built in FLAC was modified by Eq. (20-21), the van Genuchten parameter $P_{0}$ was replaced by two constant parameters, i.e. the Gallipoli parameters $\varphi$ and $\psi$ in Table 4 . The water retention parameters $a=$ $0.2275, \varphi=0.004621$, and $\psi=4.117$ were back calculated from the data for Kaolin material in Tarantino \& Tombolato (2005), and their controlled SWRC curves under various porosities are plotted in Fig. 7. The saturated mobility coefficient was modified following Eq. (27) during model solving/cycling. As the pore air pressure is fixed as atmospheric, and water is the only fluid of 
concern in the model, both the air fluid modulus and the viscosity ratio were set as 1 for convenience. The undrained coefficient $\beta$ was set as 1 to simulate constant water content $(\mathrm{CW})$ condition.

\section{Models and properties for interface}

Interfaces in FLAC are used to construct the contact planes between the infill material and the rock joint surface. The conditions of the interfaces in FLAC have three options (glued, unglued, and bonded). Here the unglued interface is chosen and the tensile bond and shear bond strength defined in FLAC manual are neglected to allow slip and/or separation along the joint-infill interface, where the Mohr-Coulomb shear-strength criterion applies:

$$
\tau_{\max }=c_{\mathrm{i}}+\sigma_{\mathrm{n}} \tan \phi
$$

where $\tau_{\text {max }}$ is maximum shear stress along the interface, $c_{\mathrm{i}}$ is cohesion, $\sigma_{\mathrm{n}}$ is normal stress applied to the interface, and $\phi$ is friction angle of interface surfaces.

The normal stress $\sigma_{\mathrm{n}}$ and shear stress $\tau_{\mathrm{s}}$ are determined by

$$
\begin{gathered}
\sigma_{\mathrm{n}}=k_{\mathrm{n}} u_{\mathrm{n}} \\
\tau_{\mathrm{s}}=\left\{\begin{array}{cc}
k_{\mathrm{s}} u_{\mathrm{s}} & k_{\mathrm{s}} u_{\mathrm{s}} \leq \tau_{\max } \\
\tau_{\max } & k_{\mathrm{s}} u_{\mathrm{s}}>\tau_{\max }
\end{array}\right.
\end{gathered}
$$

where $k_{\mathrm{n}}$ and $k_{\mathrm{s}}$ are normal and shear stiffness of the interface, and $u_{\mathrm{n}}$ and $u_{\mathrm{s}}$ are normal and shear displacement, respectively.

Both the normal stiffness and shear stiffness of the interfaces are determined using the empirical equation suggested in FLAC:

$$
k_{\mathrm{n}}=k_{\mathrm{s}}=10 \times \max \left[\frac{K+\frac{4}{3} G}{\Delta z_{\min }}\right]
$$

where $\Delta z_{\text {min }}$ is smallest width of an adjoining zone in the normal direction, which is $0.5 \mathrm{~mm}$ in the established model. 
This equation ensures that the normal stiffness is fairly large to prevent severe rock-infill surface penetration. The modulus values of the infill material (softer side of the interface) are substituted into Eq. (31) for the estimation, instead of that of the rock part, which minimises the interface influence on system compliance. Calculated stiffness values are shown in Table 3. Note that the shear stiffness is several orders higher than true physical values for the rock-infill interface. The direct effect of shear stiffness is the shear displacement before yielding of the interface. In this study, the total shear displacement in simulated tests is set as only $1.5 \mathrm{~mm}$ to avoid interference between joint asperities which is beyond the objective of this study. Hence it is less important whether the shear stiffness is true physical value or not, as long as the shear strength can be observed within such shear distance, for the convenience of analysis.

The Mohr-Coulomb strength parameters including cohesion and friction angle are selected based on general laboratory results. Those strength parameters are also summarised in Table 3 .

\section{Parametric Study}

Based on the governing models and procedures mentioned above, systematic numerical simulation was conducted under various conditions. First of all the results obtained before and after porositycorrection were compared, highlighting the significance of taking the varying infill porosity into account. Then the applied shear velocity $(v)$ to the lower rock part was optimised considering modelling stability as well as efficiency. Afterwards the influence of the initial infill saturation degree $\left(S_{\mathrm{r} 0}\right)$ on the shear behaviour was systematically investigated. The effects of other parameters such as physical shear rate $(\gamma)$, JRC, $t / a$ ratio and applied normal stress $\left(\sigma_{\mathrm{n}}\right)$ were also studied.

\section{Porosity correction}

The infill porosity influences the shear behaviour of the joints by changing the SWRC and permeability. To consider this influence, the related functions in FLAC were updated in FISH 
subroutines while model cycling. However it was too time-consuming and unnecessary to conduct the update for every calculation step and therefore less frequent updating was used. Results presented here compare the different levels of the update times in the whole shear process, ranging from zero (uncorrected for displacement of $1.5 \mathrm{~mm}$ ), to 15 times (once per $0.1 \mathrm{~mm}$ shear displacement), to 30 times (once per $0.05 \mathrm{~mm}$ ), and to 60 times (once per $0.025 \mathrm{~mm}$ ), following the modelling plan described in Table 1 (test No. 1 4). Other parameters are set as constant, with JRC $=8-10, S_{\mathrm{r} 0}=0.5, \sigma_{\mathrm{n}}=0.5 \mathrm{MPa}, t / a=0.5, v=1 \times 10^{-8} \mathrm{~m} / \mathrm{step}$, and $\gamma=0.5 \mathrm{~mm} / \mathrm{min}$.

All graphs in Fig. 8(a-e) clearly show that the shear behaviour changes significantly as long as the porosity is considered, no matter how frequent the update is. Strain softening behaviour is observed in Fig. 8(a) except for the porosity-uncorrected case (number of porosity-update time $(N)$ $=0$ ). Fig. 8 (e) shows that shear strength decreases with the increase of the updating frequency, and remains nearly stable when the number of correction times is beyond 30. As revealed in Fig. 8(b), the rock joint dilation decreases when the update frequency increases. When porosity is uncorrected, the mean values of both effective stress and saturated mobility coefficient hold steady; while the effective stress decreases significantly and the saturated mobility coefficient increases dramatically when porosity is considered. The higher the update frequency is, the lower the effective stress, and the larger the permeability.

As the influence of the correction times on the shear strength becomes minor when the number of correction times is at or beyond 30 (i.e. once per $0.05 \mathrm{~mm}$ of shear displacement), this number was used for the following simulation to study other parameters.

\section{Applied shear velocity}

To apply the appropriate shear velocity on the lower rock part that is small enough to minimise the unbalanced forces in the model, numerical tests trialling different horizontal velocities were run, 
with the velocities ranging from $1 \times 10^{-9} \mathrm{~m} / \mathrm{step}$ to $1 \times 10^{-6} \mathrm{~m} / \mathrm{step}$. Likewise, other parameters are set as constant, with JRC $=8-10, S_{\mathrm{r} 0}=0.5, \sigma_{\mathrm{n}}=0.5 \mathrm{MPa}, t / a=0.5, N=30$, and $\gamma=0.5 \mathrm{~mm} / \mathrm{min}$, as shown in Table 1 (test No. 3, 5, 6 and 7).

Fig. 9 shows the $\mathrm{xx}$-stress contours at the end of shearing under different shear velocities. It is clear that the stress is more balanced as the applied shear velocity decreases. The influence of applied velocity on the shear stress curves as well as the maximum unbalanced force during shear is also plotted in Fig. 10. With decrease of applied velocity, damping induced oscillation reduced dramatically in the shear stress vs shear displacement curves, and the plots for $1 \times 10^{-8}$ and $1 \times 10^{-9}$ $\mathrm{m} / \mathrm{step}$ almost overlap (Fig. 10(a)). On the other hand, the peak shear stress and the absolute value of mean maximum unbalanced force decrease significantly and become stable when the velocity falls lower than $1 \times 10^{-8} \mathrm{~m} / \mathrm{step}$ as shown in Fig. 10(b). Based on the curve trends, a shear velocity of $1 \times 10^{-8} \mathrm{~m} / \mathrm{step}$ was selected for the following model which was slow enough to obtain accurate results, while the model run time was kept reasonably low.

\section{Degree of saturation}

This section investigates the impacts of initial degree of saturation of the infill material on the joints shear behaviour. Tests under three levels of saturation $(50 \%, 60 \%$ and $99 \%)$ were simulated (test No. 3, 8 and 9), corresponding to water contents of $21.6 \%, 25.9 \%$, and $46.5 \%$, respectively, with JRC $=8-10, \sigma_{\mathrm{n}}=0.5 \mathrm{MPa}, t / a=0.5, \gamma=0.5 \mathrm{~mm} / \mathrm{min}, v=1 \times 10^{-8} \mathrm{~m} / \mathrm{step}$, and $N=30$.

Modelling results are plotted in Fig. 8(f-j). Typically, with the increase of the initial degree of saturation: the shear strength decreases significantly, and the strain softening behaviour after peak diminishes; dilation comes earlier; the mean effective stress decreases more gently; and the mean saturated mobility coefficient increases more. 
Undoubtedly the impact of infill saturation on the joint shear strength fits the general knowledge (Indraratna et al. 2014; Khosravi et al. 2016). As the optimum water content (OMC) of the selected material is $32 \%$ based on the laboratory results from Tarantino \& Tombolato (2005), Fig. 8(f) shows that the strain softening is clearly evident in the specimens compacted at dry of OMC, while this behaviour diminished when the water content was over OMC. Such phenomenon is also similar to laboratory results reported in literature such as Ribeiro Heitor (2013), where a series of direct shear tests were conducted on silty sand compacted at various water contents $(w=$ 8.5-16.8\%), sheared under different levels of vertical stress $(38.5,79.6$, and $146.7 \mathrm{kPa})$, and at as compacted states. Taking the tests with applied vertical stress of $38.5 \mathrm{kPa}$ as an example (Fig. 11), it can be seen that the strain softening is distinct until the water contents are over the OMC.

\section{Physical shear rate}

It should be noted that the shear velocity applied to the lower rock does not represent the shear rate for rock joints in reality, as the static analyses mode was used. However the flow calculation was in real time. Hence the influence of physical shear rate can be investigated by controlling the real flow time within a specific displacement.

In the two-phase flow mode in FLAC, the magnitude of the critical time step can be estimated using

$$
\Delta t=L_{\mathrm{z}}^{2} n \min \left(\frac{1}{k_{\mathrm{w}} K_{\mathrm{w}}}, \frac{1}{k_{\mathrm{g}} K_{\mathrm{g}}}\right)
$$

where $L_{\mathrm{z}}$ is the smallest zone size in the model $(0.5 \mathrm{~mm})$, and $k_{\mathrm{w}}$ and $k_{\mathrm{g}}$ are the saturated mobility coefficients for water and air respectively.

Hence in the coupled analysis, the number of flow steps corresponding to each mechanical step is

$$
N_{\mathrm{gw}}=\frac{v}{\gamma \Delta t}
$$


where $N_{\mathrm{gw}}$ is the number of flow steps for each mechanical step, $v$ is applied shear velocity $\left(1 \times 10^{-}\right.$ ${ }^{8} \mathrm{~m} / \mathrm{step}$ ), and $\gamma$ is the simulated physical shear rate.

The influence of the physical shear rate was then investigated by following $N_{\mathrm{gw}}$ numbers of flow step after each mechanical step in the model solving controlled by FISH subroutine. Note that $N_{\mathrm{gw}}$ will vary with porosity during shear since the saturated mobility coefficient $k_{\mathrm{w}}$ is porosityrelated; the value of $N_{\mathrm{gw}}$ is then updated together with porosity, saturated mobility coefficient and SWRC during stepping. Shear behaviour under three levels of physical shear rate were investigated $(5,0.5$, and $0.005 \mathrm{~mm} / \mathrm{min})$, selected within the range usually adopted in the laboratory tests as described in literature (de Toledo \& de Freitas 1993; Indraratna et al. 2014; Khosravi et al. 2016). As the constant water content $(\mathrm{CW})$ condition is applied, the impacts of physical shear rate reflect the influence of the degree of suction equilibrium, i.e. the degree of the inhomogeneous suction distribution inside the infill layer. The effect of pore pressure drainage was not studied which can be done by changing the input value of undrained coefficient.

A series of tests were modelled (test No. 3, 10 and 11), using JRC $=8-10, S_{\mathrm{r} 0}=0.5, \sigma_{\mathrm{n}}=$ $0.5 \mathrm{MPa}, t / a=0.5$, and $v=1 \times 10^{-8} \mathrm{~m} / \mathrm{step}$ on the lower rock part. Fig. 12 shows the pore water pressure (negative suction) contours within the soil layer under different physical shear rates at the end of shearing. The plot indicates that under the selected physical shear rates, matric suction failed to be in equilibrium during shear. With the increase in shear rate, the suction distribution at the end of the tests becomes less homogeneous, but the differences are not that large. Fig. $8(\mathrm{k})$ clearly shows that the influence of physical shear rate (suction equilibrium time) on the shear stress curves are minor. After zooming and smoothing those curves replotted in Fig. 13(a-b), the obtained shear strength in Fig. 8(o) reveals a slight decreasing trend with the decrease of physical shear rate. This is in consistence with the laboratory test results obtained by de Toledo \& de Freitas (1993), where 
the influence of shear rate on the peak strength of an infilled joint with free draining boundaries are investigated. As shown in Fig. 14, once the shear rate is relatively high so that undrained condition applies, its influence on the joint shear strength becomes small. In terms of other parameters shown in Fig. 8(1-n), the curves almost overlap before shear stress reach the peak value; after peak, the difference between the curves becomes visible and gradually larger. Generally the higher the physical shear rate, the larger the dilation, mean effective stress and saturated mobility coefficient.

$J R C$

A series of numerical tests (test No. 3,12 and 13) were conducted afterwards under three levels of JRC (planar, JRC=8-10 and JRC=18-20). Similarly, all other conditions were kept constant, with $S_{\mathrm{r} 0}=50 \%, \sigma_{\mathrm{n}}=0.5 \mathrm{MPa}, t / a=0.5, \gamma=0.5 \mathrm{~mm} / \mathrm{min}, v=1 \times 10^{-8} \mathrm{~m} / \mathrm{step}$, and $N=30$.

Test results are displayed in Fig 15(a-e). Firstly it can be seen that shear strength increases with the increase of joint roughness (Fig. 15(e)), even though the joint asperities have not interfered. This is because the rougher joint profile enhances the apparent sliding friction between joint and infill (de Toledo \& de Freitas 1993), while it produces highly inhomogeneous and concentrated normal stress on the infill material along the interface (Fig. 16). Such phenomenon also agrees well with shear tests on soil - rock/concrete interfaces conducted by Kanji (1974) and Chen et al. (2015), where the surface roughness clearly has a positive effect on the interface shear strength, regardless of the lack of asperity interference (infill thickness can be considered as infinite for those tests). In addition, the shear displacement needed to reach residual strength is smaller for joints with smoother surfaces as shown in Fig. 15(a), which is also in accordance with the results of Kanji (1974). In terms of the dilation behaviour displayed in Fig. 15(b), the planar joints show a continuous contraction, while other two rough joints reveal distinct dilation after initial 
compression. It seems the roughest joint fails to have the largest dilation which is beyond intuition. This is because at the stage before asperity interference, increased joint roughness influences the normal displacement through two mechanisms: enhanced resistance to infill squeezing/flow which reduces the contraction, and increased stress concentration on some parts of the infill which leads to increased compaction. The variation trends of the normal displacement under different joint roughness depend on which mechanism is dominant. Accordingly, the mean values of saturated mobility coefficient show distinct patterns in planar and rough joints, and not perfectly monotonous when joint roughness increases. Generally the variation range becomes much larger for the joints with JRC $=8-10$ and 18-20, compared with the planar joint. In terms of the mean effective stress, the rougher the joint surface, the lower the values.

\section{t/a ratio}

Tests under various $t / a$ ratios $(0.5,1.0$, and 1.5$)$ were simulated (test No. 3,14 and 15$)$ and the obtained model results can be seen in Fig. 15(f-j). Again, all other parameters were kept constant when changing the infill thickness, with $S_{\mathrm{r} 0}=50 \%, \sigma_{\mathrm{n}}=0.5 \mathrm{MPa}, \mathrm{JRC}=8-10, \gamma=0.5 \mathrm{~mm} / \mathrm{min}, v$ $=1 \times 10^{-8} \mathrm{~m} / \mathrm{step}$, and $N=30$. It is obvious that with the increase of $t / a$ ratio, shear strength decreases almost linearly, the infill layer is compressed more, and the changes in effective stress and saturated mobility coefficient both become gentler.

As this study only focuses on the "first stage" of the shear failure of infilled joints (Barton \& Choubey 1977; de Toledo \& de Freitas 1993), Fig. 15(j) suggests that even the "soil peak" is sensitive to the $t / a$ ratio. In fact similar trends can be found in many other researchers' laboratory results (de Toledo \& de Freitas 1993; Indraratna et al. 1999). This is because with the increase of $t / a$ ratio, the obstruction from the rough joint profile against the infill squeezing (flow) becomes 
weaker, and the maximum stress concentration factor within the infill layer decreases, as indicated in Fig. 17(a-b).

\section{Normal stress}

The factor of normal stress was also investigated afterwards. Three levels of applied normal stress (0.5 MPa, 1.0MPa, and 1.5MPa) were selected and the shear tests were modelled with $S_{\mathrm{r} 0}=50 \%$, $t / a=0.5, \mathrm{JRC}=8-10, \gamma=0.5 \mathrm{~mm} / \mathrm{min}, v=1 \times 10^{-8} \mathrm{~m} / \mathrm{step}$, and $N=30$ (test No. 3, 16 and 17). Those levels of normal stress simulate not only a shallow depth of about $20-60 \mathrm{~m}$, but also the loading conditions deep underground. During and after excavation deep underground, the residual normal stress applied to the infilled joints could be much lower than in situ state, as the surrounding rock deforms, bulks and displaces into the mined cavity causing unloading of those joints.

As expected, with the increase of applied normal stress, shear strength increases noticeably (Fig. 15(k) and 15(o)), the infill layer is dilated less (Fig. 15(l)), and the mean saturated mobility coefficient is increased more (Fig. 15(n)). Fig. 15(m) shows that the decrease of mean effective stress becomes larger when normal stress increases from $0.5 \mathrm{MPa}$ to $1.0 \mathrm{MPa}$, and then remains almost the same when it increases from 1.0MPa to $1.5 \mathrm{MPa}$.

\section{Summary and practical implications}

In summary, this paper employed the FLAC Two-Phase flow mode to conduct a series of direct shear tests under constant normal load and constant water content conditions. Particularly the soil water retention curve and permeability constitutive models in FLAC were modified by considering porosity where the porosity updating frequency in FLAC calculation was optimised. The effects of initial infill saturation degree were then studied under the selected porosity update times and shear velocity. Other parameters including physical shear rate, joint roughness, $t$ /a ratio and normal 
stress were also investigated. Typical modelling results are summarised here, with some practical implications emphasised:

(a) The results highlight the shortcomings of the built-in models in FLAC that does not include porosity change. Porosity correction significantly changes the mean effective stress and the shear stress values from steady state towards a strain softening behaviour. This indicates that if FLAC is used directly without porosity correction, the residual shear strength of the infilled joints may be significantly overestimated. In practice, this could cause an unsafe support design for the jointed rock excavations.

(b) The variations of shear stress, normal displacement, and the mean values of Bishop effective stress and saturated mobility coefficient within the infill, all showed similar trends during shear, regardless of varying conditions. It should be noted that both the degree of saturation and matric suction also varied in the shear process which changed the Bishop effective stress jointly. To be brief, only the curves of Bishop effective stress are plotted in this paper. For the mated infilled joints investigated here, shear stress reaches peak soon after shearing begins and then holds steady or decreases to a residual value and in both cases eventually increase again as the asperities come into contact. Noticeable infill compression occurs after initial minor dilation, followed by continued compression or distinct dilation (if the asperities meet). Bishop effective stress increases slightly at the start, and then decreases significantly while all saturated mobility coefficients grow exponentially. General trends of these variables are summarised in Table 5 for easy comparison.

Most importantly, the results shown in Table 5 indicate that shear movement along the infilled joints decreases the Bishop effective stress within the infill, which leads to a reduction of the joint shear strength. In practice, rock joints could undergo intermittent shear for a long 
time as rock expands into cavities after excavation, and shear strength may become much lower compared with initial states. If the support design neglects such variations, undesirable deformation of the surrounding rock may occur with time. This could lead to ground instability at a later stage, causing safety issues and economic losses. The post-peak exponential increase in the infill permeability also plays a potentially important role in gas outbursts/explosions and recovery in underground coal mines.

(c) The modelling results of various parameters under different infill degree of saturation, physical shear rate, JRC, t/a ratio and normal stress all show reasonable trends. Note that this study refers to relatively low normal stress conditions that exist not only in the shallow depth but also deep underground where surrounding-rock softening/yielding has been experienced. Typical results of these parameters are summarised in Table 6 .

Some significant practical implications based on Table 6 are emphasised here. (i) The infill degree of saturation study shows that shear strength increases noticeably when the degree of saturation decreases. When assessing the surrounding rock stability in mining, the infilled discontinuities tend to be simply assumed as fully saturated. However, in some arid regions or zones with low water discharge, the jointed rock mass may be under stable unsaturated conditions exhibiting larger strength. Therefore in dryer conditions the safety factor of the overall ground support design could be higher. (ii) The physical shear rate has little effect on the joint shear behaviour in undrained condition within the range simulating static loading. In other words, when conducting shear tests of unsaturated infill joints under rigid undrained laboratory conditions, it may not be necessary to use an extremely low shear rate (e.g. several $\mathrm{mm} /$ day) to ensure suction equilibrium. (iii) The shear stress-displacement results show that the peak shear stress for infilled joints is sensitive to JRC and $t / a$ ratio even before the asperities 
come into contact. This is important particularly in some circumstances where shear deformation needed for asperities to contact is very large already. Hence, not only the peak shear stress achieved after asperity contact but also the peak stress before contact should be considered in the stability evaluation and reinforcement design.

\section{Conclusions}

This study proposed a general framework of modelling the shear behaviour of rock joints filled with unsaturated soil. The influences of various parameters including initial saturation degree, physical shear rate, joint roughness, t/a ratio and normal stress versus the shear stress, normal displacement, Bishop effective stress and permeability in the constant normal load and constant water content direct shear tests were studied. To the authors' knowledge this is the first time the infill degree of saturation and porosity is taken into account when numerically modelling the infilled joint shear behaviour. Some important conclusions can be drawn:

(a) Porosity correction in FLAC Two-Phase flow mode is essential as the original constitutive models overestimate the residual shear strength in unsaturated joint infills.

(b) General varying trends of shear stress, normal displacement, and the mean values of Bishop effective stress and saturated mobility coefficient with shear displacement are relatively similar, regardless of different conditions. Particularly, the mean effective stress decreases during shear, while the saturated mobility coefficients grow exponentially.

(c) Shear strength increased significantly when the initial degree of saturation decreased. Effects of other parameters (i.e. physical shear rate, joint roughness, t/a ratio and normal stress) on the joint shear strength all agree well with previous laboratory results.

(d) Physical shear rate within the range simulating static loading has little effects on the joint shear behaviour. 
(e) The peak shear stress in the shear stress-displacement curve for infilled joints is sensitive to $\mathrm{JRC}$ and $\mathrm{t} / \mathrm{a}$ ratio even before the asperities come into contact.

There are some limitations of this study. (a) The Mohr-Coulomb model used for the unsaturated infill material does not accurately describe its volumetric strain. (b) Hydraulic hysteresis of the SWRC was neglected. (c) Only the shear behaviour before joint asperities came into contact was studied, which applies mainly to the mated infill joints that formed by tensile opening and infilled before shearing occurred. (d) The infill-rock interface was simply assumed as impermeable, while this may not be true in reality. (e) Despite that the effects of various investigated parameters on the joint shear strength and some other modelling results agree well with previous literature reports in a qualitative matter, the obtained changing trends of mechanical/hydraulic variables were not verified quantitatively by laboratory investigations, due to performing and measuring difficulties. (f) The influences of various parameters on the macro equivalent Coulomb strength parameters (i.e. cohesion and friction angle) were not studied. (g) The influences of dynamic loading, constant normal stiffness loading, drainage conditions and specimen scale were not studied.

Future research should consider more accurate constitutive models for unsaturated soils to be embedded in FLAC through FISH subroutines, so that the deformation and strength of infilled joints can be simulated more precisely. In addition, tests under more levels of applied normal stress need to be modelled for each investigated parameter, so that the changing rules of strength envelopes and macro equivalent Coulomb parameters can be analysed. In terms of laboratory verifications to the numerical work described in this paper, the following modifications to the conventional direct shear apparatus (ASTM D5607-16, Muralha et al. 2013) for rock joints should be taken into account: (a) seal the specimen and add a lateral confinement around the infill layer with some membranes or stacked plates; (b) enlarge the specimen so that the infill layer is 
relatively thick, which is not only essential for preparing specimens with accurate infill thickness, porosity and water content, but also beneficial for accurate measurements of all kinds of variables during shear; (c) directly measure the infill matric suction while testing by installing rigid suction sensors (e.g. high-capacity tensiometers) inside the specimens.

\section{Acknowledgements}

The financial support provided by the China Scholarship Council [Grant No. 201406420027] and University of Wollongong for the first author is greatly appreciated.

\section{References}

Alonso, E. E., Zandarín, M. T., and Olivella, S. (2013). “Joints in unsaturated rocks: thermo-hydromechanical formulation and constitutive behaviour." Journal of Rock Mechanics and Geotechnical Engineering, 5(3), 200-213.

ASTM D5607-16. (2016). "Standard test method for performing laboratory direct shear strength tests of rock specimens under constant normal force”, ASTM International, West Conshohocken, PA.

Barton, N. (1974). “A review of the shear strength of filled discontinuities in rock.” Publ. No. 105, Norwegian Geotech. Inst., Oslo, 1-38.

Barton, N. and Bandis, S. C. (2017). "Characterization and modeling of the shear strength, stiffness and hydraulic behavior of rock joints for engineering purposes.” Rock Mechanics and Engineering Volume 1: Principles, 1-40.

Barton. N., and Choubey. V. (1977). "The shear strength of rock joints in theory and practice." Rock Mech., 10(1-2), 1-54.

Barton, N., Lien, R., and Lunde, J. (1974). "Engineering classification of rock masses for the design of tunnel support.” Rock mechanics, 6(4), 189-236. 
Brady, B. H., and Brown, E. T. (2013). Rock mechanics: for underground mining, Springer, Dordrechts, Netherlands.

Carrier, W. D., and Beckman, J. F. (1984). "Correlations between index tests and the properties of remoulded clays." Géotechnique, 34(2), 211-228.

Chen, X., Zhang, J., Xiao, Y., and Li, J. (2015). "Effect of roughness on shear behavior of red clayconcrete interface in large-scale direct shear tests." Canadian Geotechnical Journal, 52(8), $1122-1135$.

Chiu, C. C., Weng, M. C., and Huang, T. H. (2016). "Modeling rock joint behavior using a roughjoint model.” International Journal of Rock Mechanics and Mining Sciences, 89, 14-25.

Cho, S. E. (2016). "Stability analysis of unsaturated soil slopes considering water-air flow caused by rainfall infiltration.” Engineering Geology, 211, 184-197.

Choi, S. O., and Chung, S. K. (2004). "Stability analysis of jointed rock slopes using the BartonBandis constitutive model in UDEC.” Int. J. Rock Mech. Min. Sci., 41(3), 469.

Davies, O., Rouainia, M., Glendinning, S., Cash, M., and Trento, V. (2014). "Investigation of a pore pressure driven slope failure using a coupled hydro-mechanical model.” Engineering Geology, 178, 70-81.

de Toledo, P. E. C., and de Freitas, M. H. (1993). "Laboratory testing and parameters controlling the shear strength of filled rock joints." Géotechnique, 43(1), 1-19.

Duriez, J., Darve, F., and Donze, F. V. (2011). “A discrete modeling-based constitutive relation for infilled rock joints." International Journal of Rock Mechanics and Mining Sciences, 48(3), $458-468$.

Gallipoli, D., Bruno, A. W., D’Onza, F., and Mancuso, C. (2015). “A bounding surface hysteretic water retention model for deformable soils." Géotechnique, 65(10), 793-804. 
Hashem, E. B., and Houston, S. L. (2016). "Volume change consideration in determining unsaturated soil properties for geotechnical applications." International Journal of Geomechanics, 10.1061/(ASCE)GM.1943-5622.0000586, D4015003.

Indraratna, B., Aziz, N. I., and Dey, A. (2001). "Behaviour of joints containing clay infill under constant normal stiffness, with and without bolting." Proceedings of the Institution of Civil Engineers - Geotechnical Engineering, 149(4), 259-267.

Indraratna, B., Haque, A., \& Aziz, N. (1999). "Shear behaviour of idealized infilled joints under constant normal stiffness." Géotechnique, 49(3), 331-355.

Indraratna, B., Oliveira, D. A. F., and Brown, E.T., (2010). “A shear-displacement criterion for soil-infilled rock discontinuities." Géotechnique, 60(8), 623-633.

Indraratna, B., Premadasa, W., Brown, E. T., Gens, A., and Heitor, A. (2014). "Shear strength of rock joints influenced by compacted infill.” International Journal of Rock Mechanics and Mining Sciences, 70, 296-307.

ISRM (International Society for Rock Mechanics). (1981). Suggested methods for the quantitative description of discontinuites in rock masses. In: Brown, E. T., editor. Rock characterisation, testing and monitoring - ISRM suggested methods, Pergamon, Oxford, 319-368.

Itasca Consulting Group. (2011). FLAC, fast lagrangian analysis of continua, version 7.0, Minneapolis, MN.

Kanji, M. A. (1974). "Unconventional laboratory tests for the determination of the shear strength of soil-rock contacts.” Proc., 3rd Congr. Int. Soc. Rock Mech., Denver, 2, 241-247.

Khosravi, A., Serej, A. D., Mousavi, S. M., and Haeri, S. M. (2016). "Effect of hydraulic hysteresis and degree of saturation of infill materials on the behavior of an infilled rock fracture." International Journal of Rock Mechanics and Mining Sciences, 88, 105-114. 
Lu, Y., Wang, L., Li, Z., and Sun, H. (2017). “Experimental Study on the Shear Behavior of Regular Sandstone Joints Filled with Cement Grout.” Rock Mechanics and Rock Engineering, 50(5), $1321-1336$.

Ma, S. Q., Zhao, Z. Y., Nie, W., Nemcik, J., Zhang, Z. Y., and Zhu, X. (2017). “Implementation of displacement-dependent Barton-Bandis rock joint model into discontinuous deformation analysis." Comput Geotech, 86, 1-8.

Mašín, D. (2010). "Predicting the dependency of a degree of saturation on void ratio and suction using effective stress principle for unsaturated soils.” Int. J. Numer. Analyt. Methods Geomech., 34(1), 73-90.

Matray, J. M., Savoye, S., and Cabrera, J. (2007). "Desaturation and structure relationships around drifts excavated in the well-compacted Tournemire's argillite (Aveyron, France).” Engineering Geology, 90(1), 1-16.

Muralha, J., Grasselli, G., Tatone, B., Blümel, M., Chryssanthakis, P., and Yujing, J. (2013). ISRM suggested method for laboratory determination of the shear strength of rock joints: revised version. In The ISRM Suggested Methods for Rock Characterization, Testing and Monitoring: 2007-2014 (131-142). Springer, Cham.

Phien-Wej, N., Shrestha, U. B., and Rantucci, G. (1990). "Effect of infill thickness on shear behaviour of rock joints." Rock joints: proceedings of the international symposium on rock joints, Barton. N. and Stephansson. O., eds, Loen, Norway, 289-294.

Ribeiro Heitor, A. P. (2013). Assessment of post-compaction characteristics of an unsaturated silty sand, Doctoral Thesis, University of Wollongong, NSW, Australia. 
Saaltink, M. W., Ayora, C., and Olivella, S. (2005). User's guide for RetrasoCodeBright (RCB). Dept. of Geotechnical Engineering and GeoSciences, Institute of Earth Sciences Jauma Almera, Technical Univ. of Catalonia, Barcelona, Spain.

Tarantino, A., and Tombolato, S. (2005). "Coupling of hydraulic and mechanical behaviour in unsaturated compacted clay." Géotechnique, 55(4), 307-317.

Thode. R. and Fredlund. M. (2009). SVOffice user's manual, SoilVision Systems Ltd., Saskatoon, SK, Canada.

Vadose zone modeling with VADOSE/W, an engineering methodology. (2014). GEO-SLOPE International Ltd., Calgary, AB, Canada.

Vanapalli. S. K., Fredlund. D. G., and Pufahl. D. E. (1996). "The relationship between the soilwater characteristic curve and the unsaturated shear strength of a compacted glacial till." Geotechnical Testing Journal, 19(3), 259-268.

Wu, Q., An, Y., \& Liu, Q. Q. (2015). “SPH-based simulations for slope failure considering soilrock interaction.” Procedia Engineering, 102, 1842-1849.

Yu, Y., and Bathurst, R. J. (2017). "Influence of Selection of Soil and Interface Properties on Numerical Results of Two Soil-Geosynthetic Interaction Problems." International Journal of Geomechanics, 10.1061/(ASCE)GM.1943-5622.0000847, 04016136.

Yu, Y., Damians, I. P., and Bathurst, R. J. (2015). "Influence of choice of FLAC and PLAXIS interface models on reinforced soil-structure interactions." Computers and Geotechnics, 65, $164-174$. 
(a) Open cut mine slope
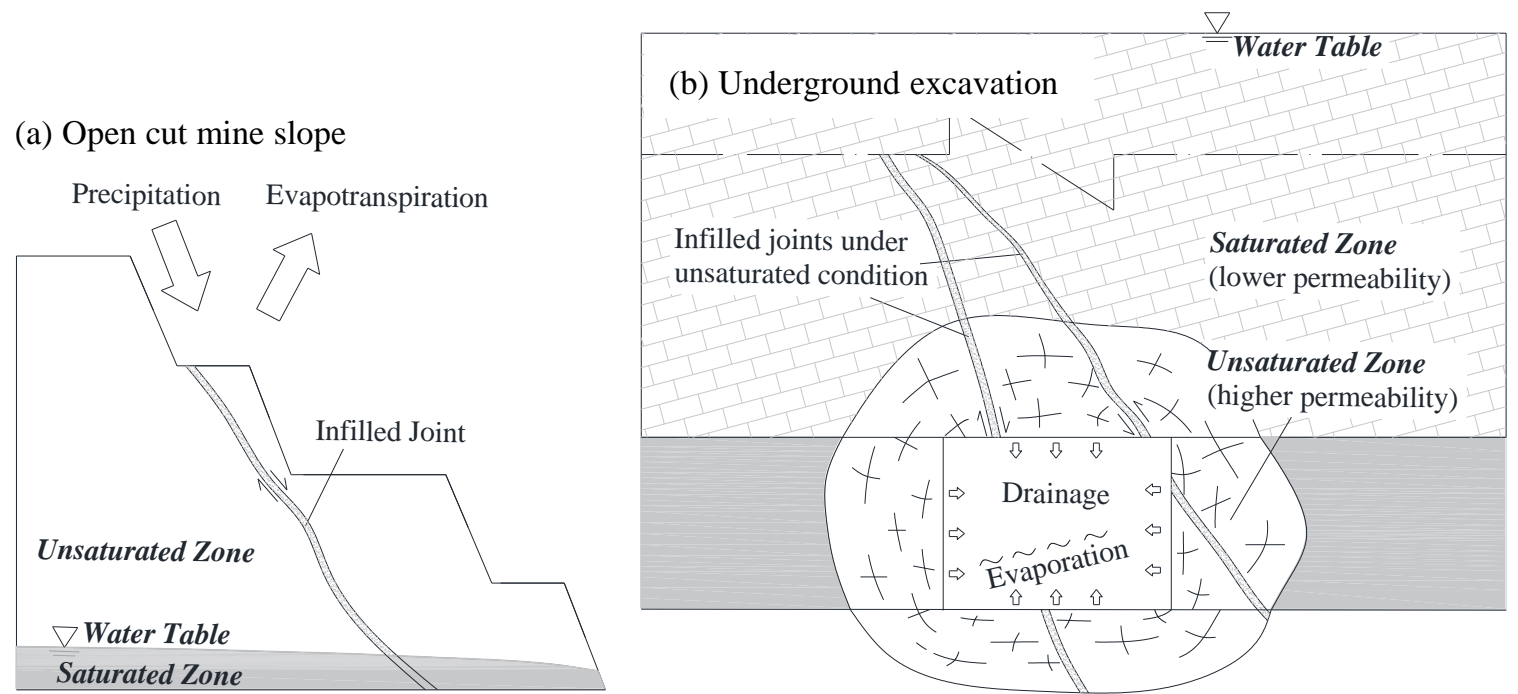

Fig. 1. Infilled joints under unsaturated conditions in mining engineering
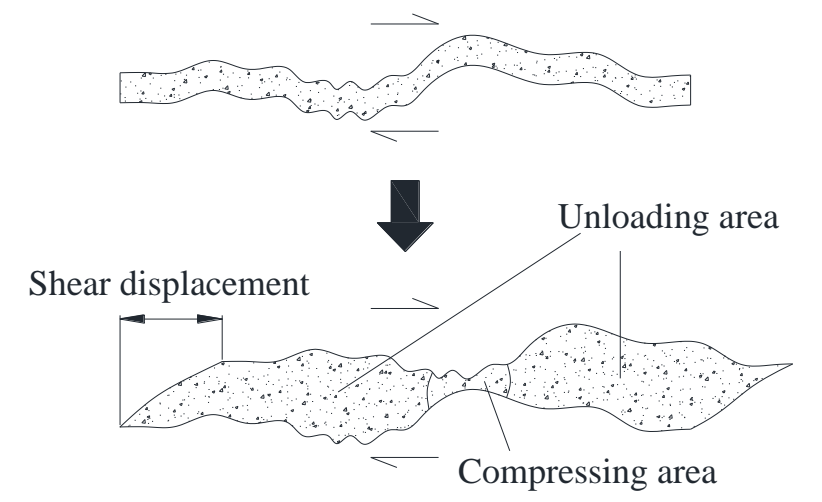

Fig. 2. Possible compressing and unloading areas within the rough joint infill during shear 


\begin{tabular}{|c|c|}
\hline$J R C$ Ranges & Barton's Standard Roughness Profiles \\
\hline $0-2$ & \\
\hline $2-4$ & \\
\hline $4-6$ & \\
\hline $6-8$ & $\vdash$ \\
\hline $8-10$ & \\
\hline $10-12$ & \\
\hline $12-14$ & \\
\hline $14-16$ & \\
\hline $16-18$ & \\
\hline $18-20$ & \\
\hline Scale $(\mathrm{cm})$ & 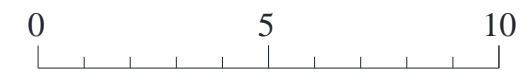 \\
\hline
\end{tabular}

Fig. 3. Typical roughness profiles and corresponding JRC values (Reprinted from Barton and Choubey 1977.) 


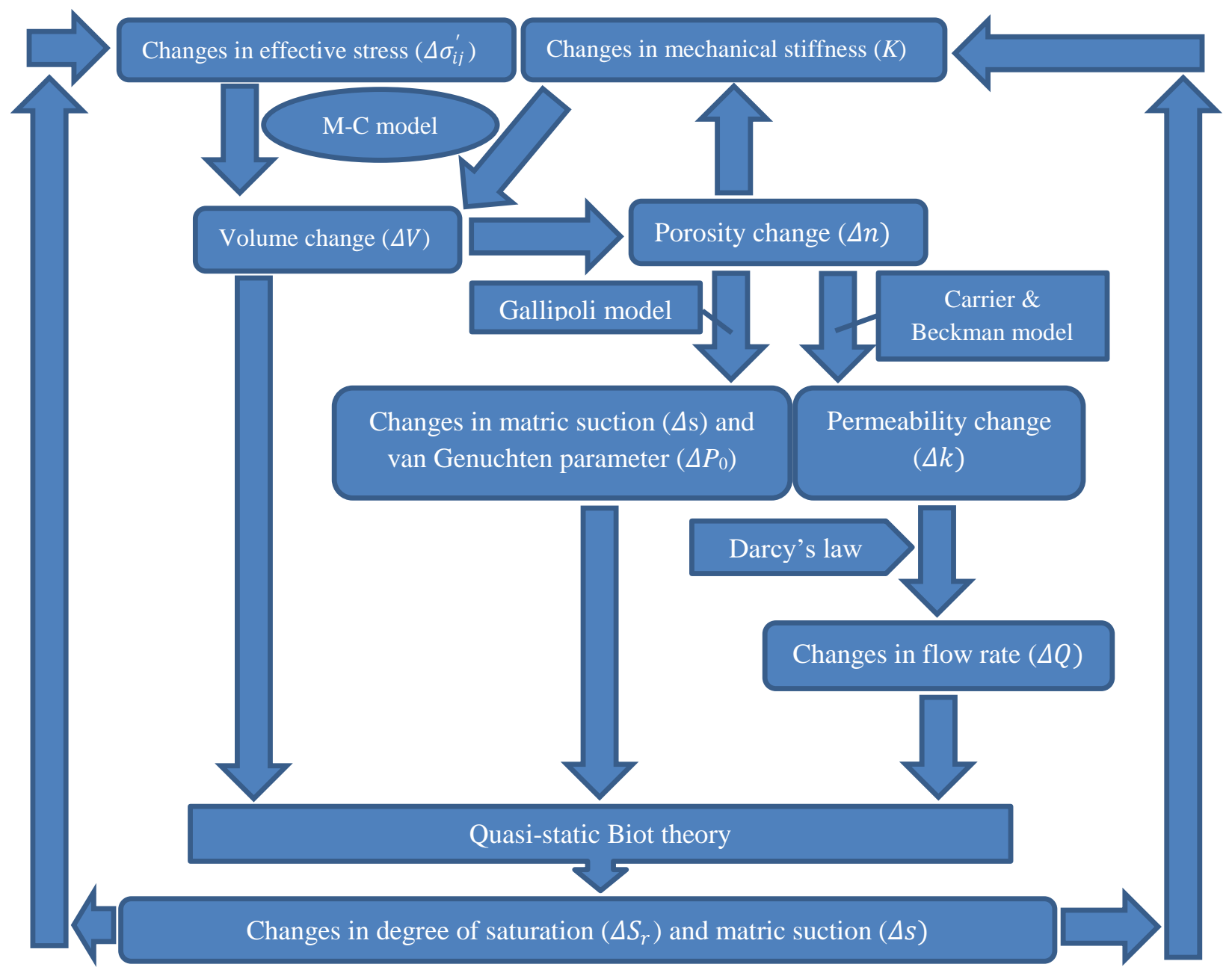

Fig. 4. Hydro-mechanical coupling in FLAC calculation cycle 
(a-c): different JRCs under similar infill thickness $t$
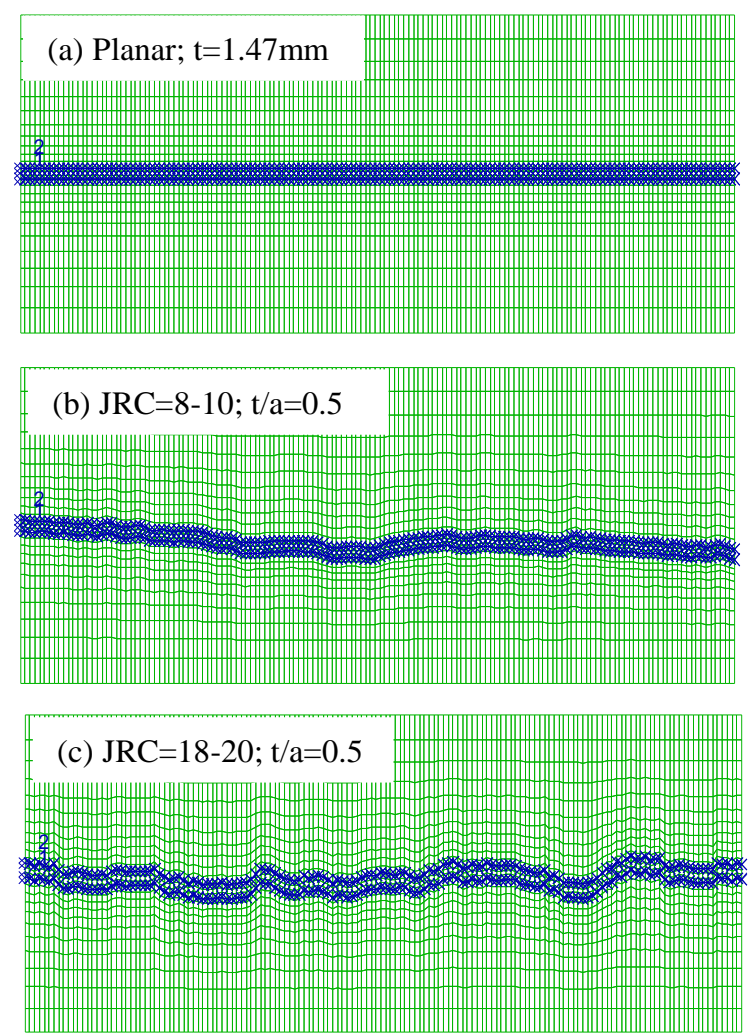

(d-e): different t/a ratios at the same JRC
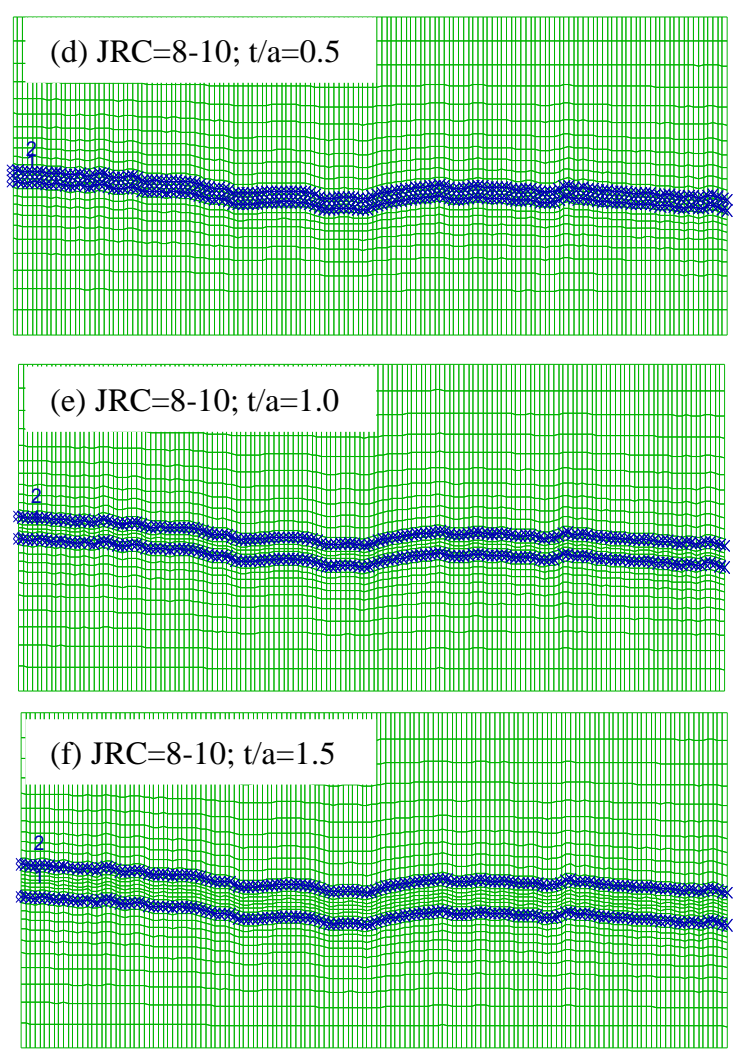

Fig. 5. Grid and interface plots of initial models

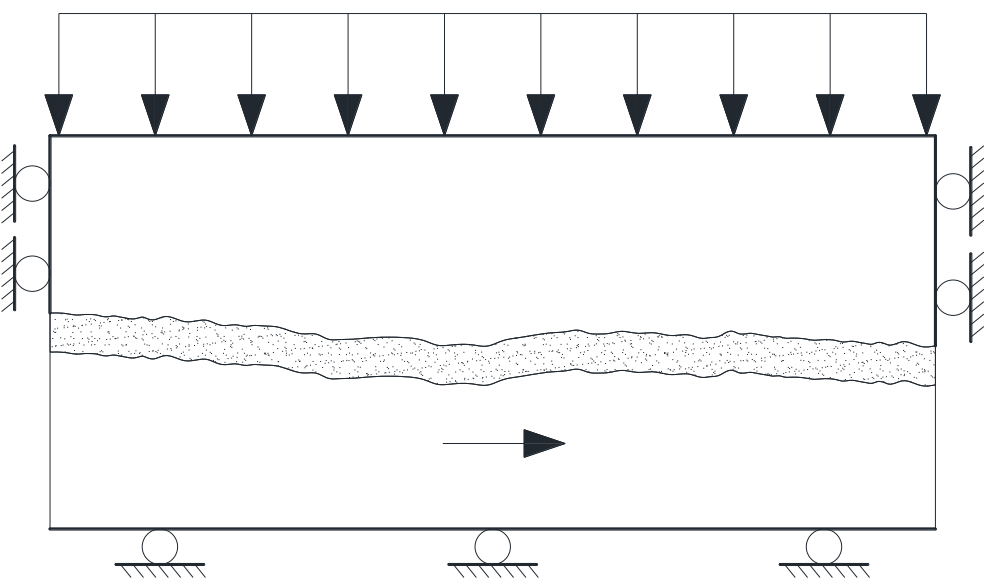

Fig. 6. Boundary conditions of the model 


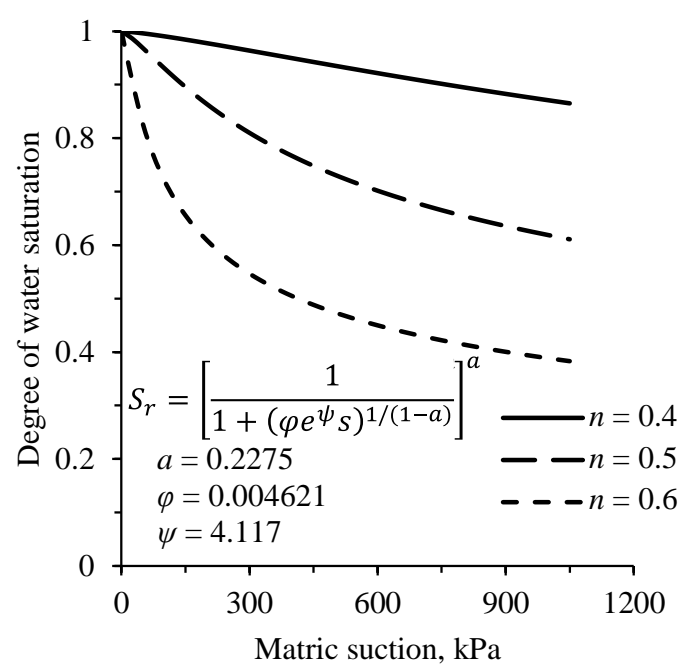

Fig. 7. Porosity-related water retention curves (Data from Tarantino and Tombolato 2005.) 


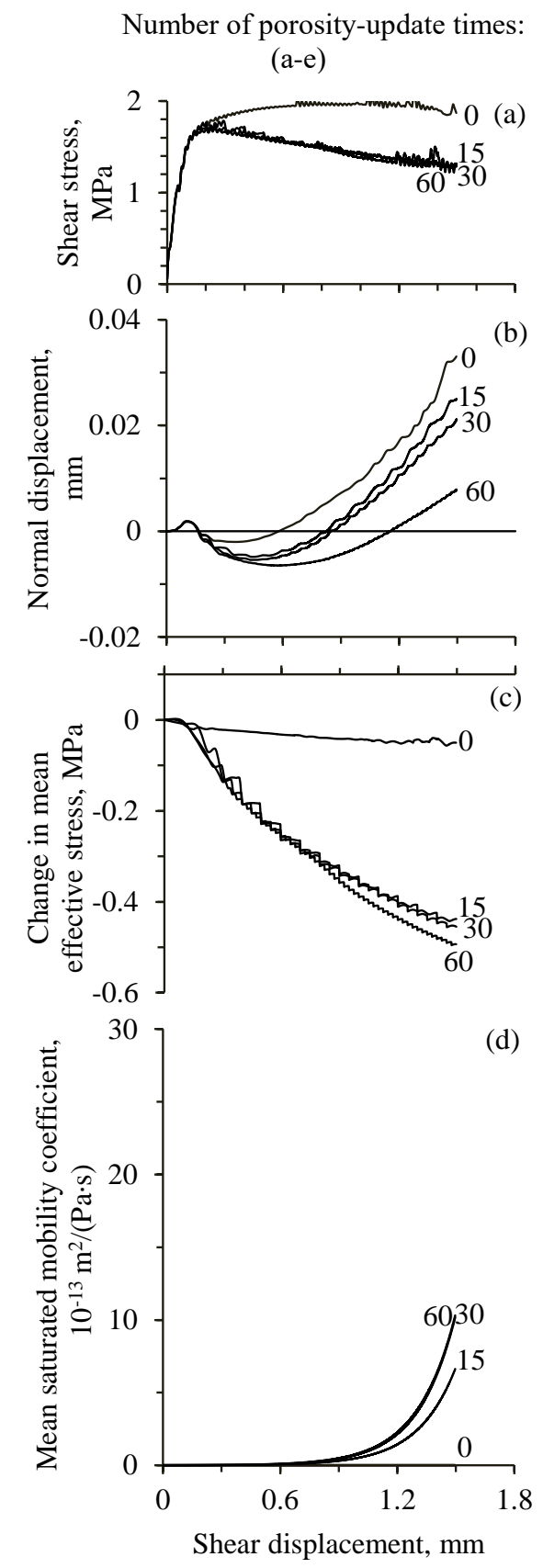

Initial degree of saturation:

Physical shear rate $(\mathrm{mm} / \mathrm{min})$ :

(f-j)

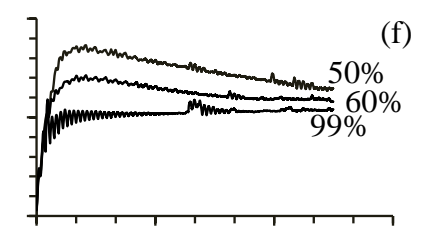

b)
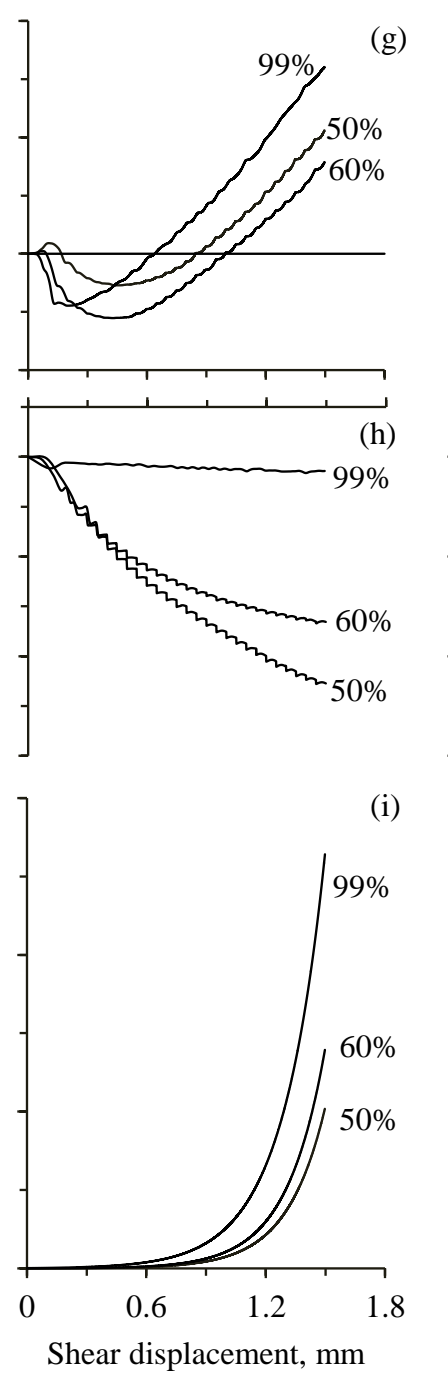

(k-o)

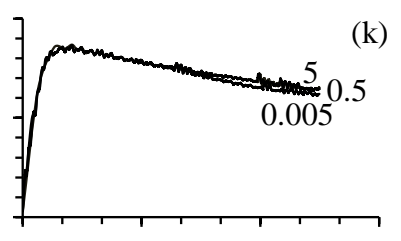

(1)

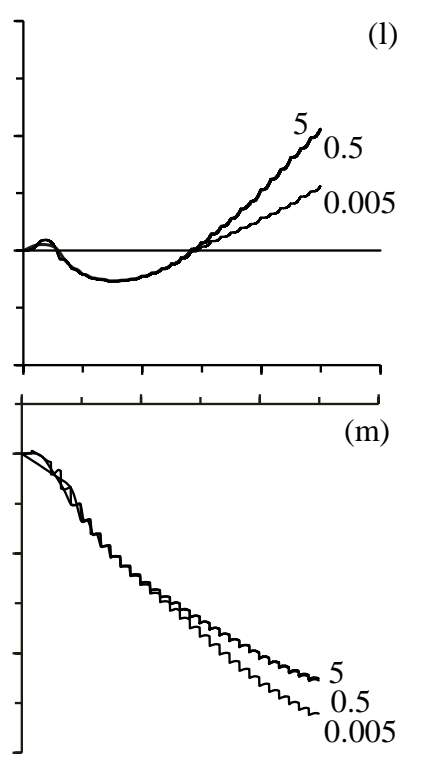

(n)

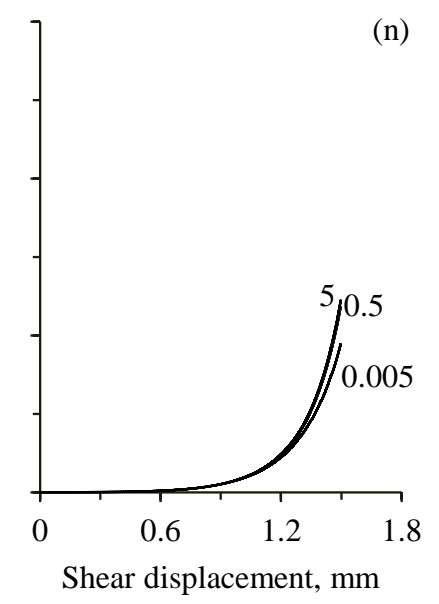

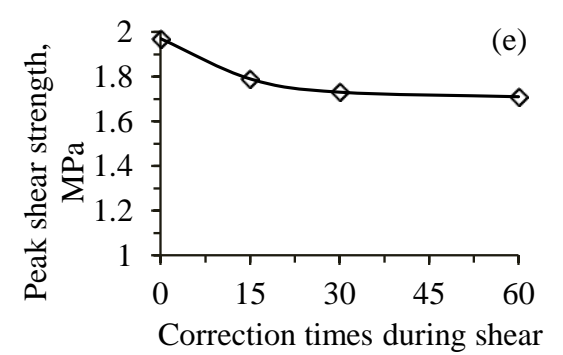
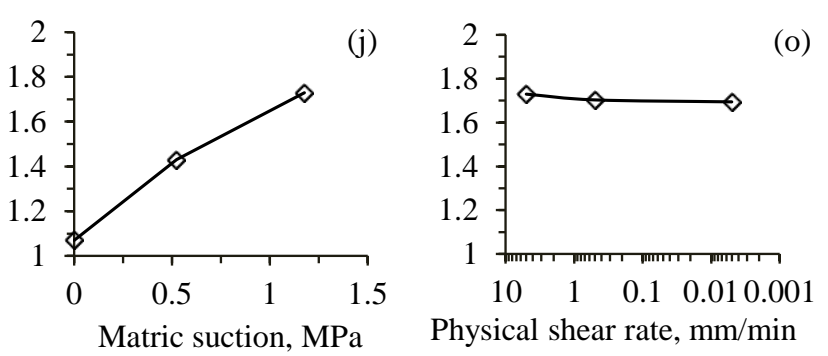

Fig. 8. Shear behaviour of infilled joints under $(a-e)$ different levels of porosity-update times, (f-j); initial infill degree of saturation, and $(\mathrm{k}-\mathrm{O})$ physical shear rate $(\mathrm{mm} / \mathrm{min})$ 


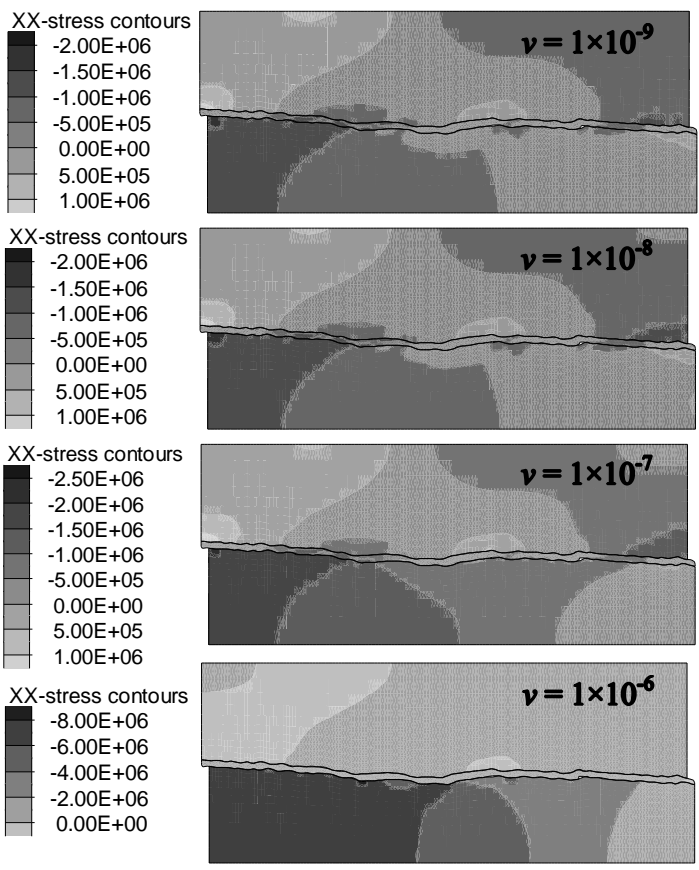

Fig. 9. xx-stress contours at the end of shearing under different mechanical shear velocities
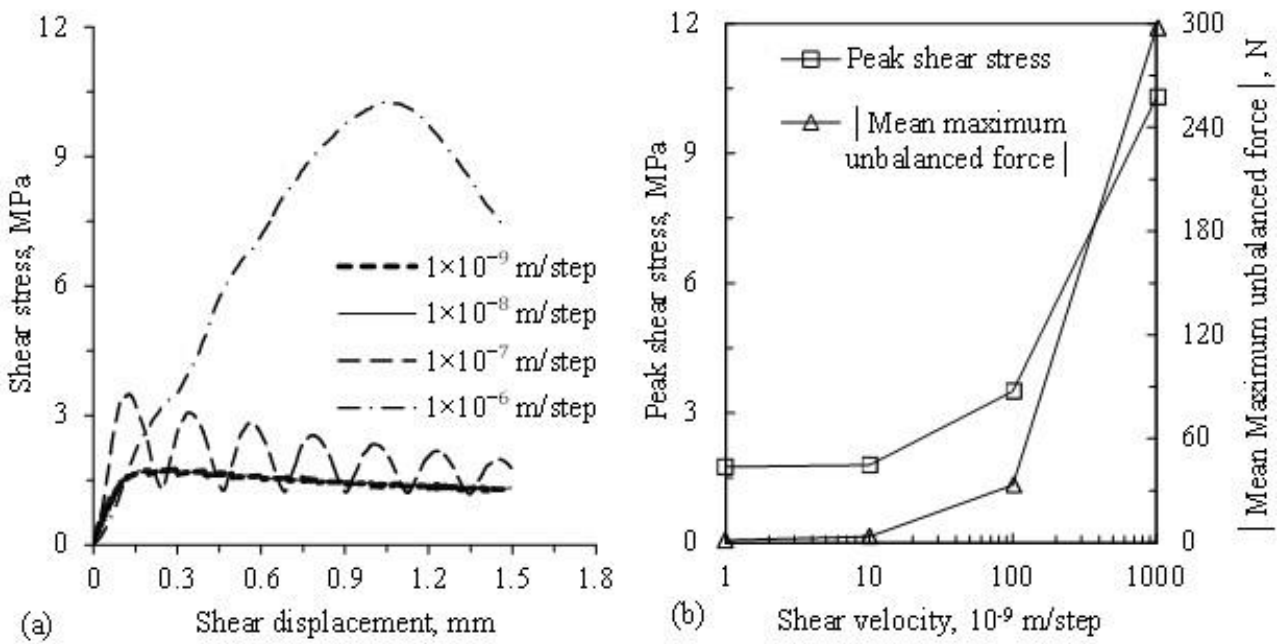

Shear displacement, $\mathrm{mm}$

(b) Shear velocity, $10^{-9} \mathrm{~m} / \mathrm{step}$

Fig. 10. Shear under different applied velocities: (a) shear stress curves; (b) peak shear stress and mean maximum unbalanced force vs applied velocity
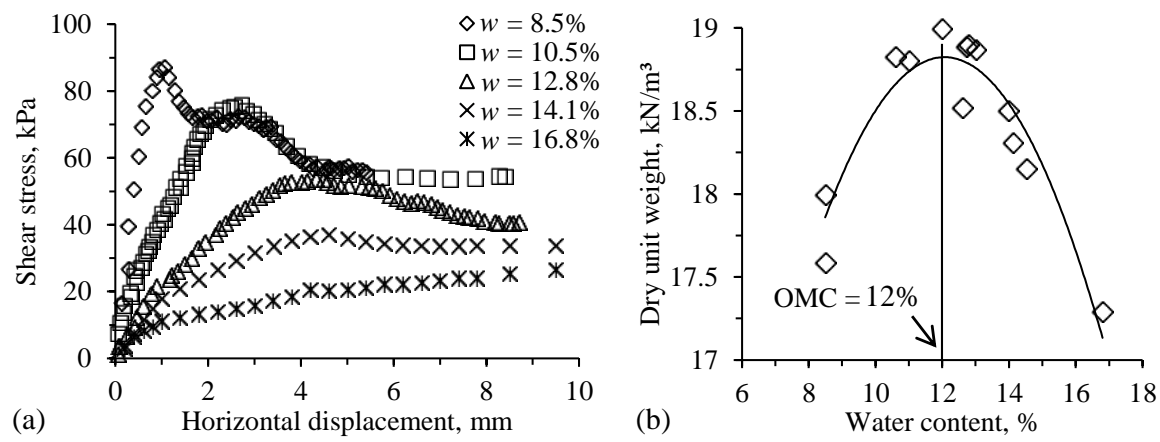

Fig. 11. Shear stress and compaction curves for a silty sand: (a) shear stress vs horizontal displacement; (b) compaction curve. (data from Ribeiro Heitor 2013) 


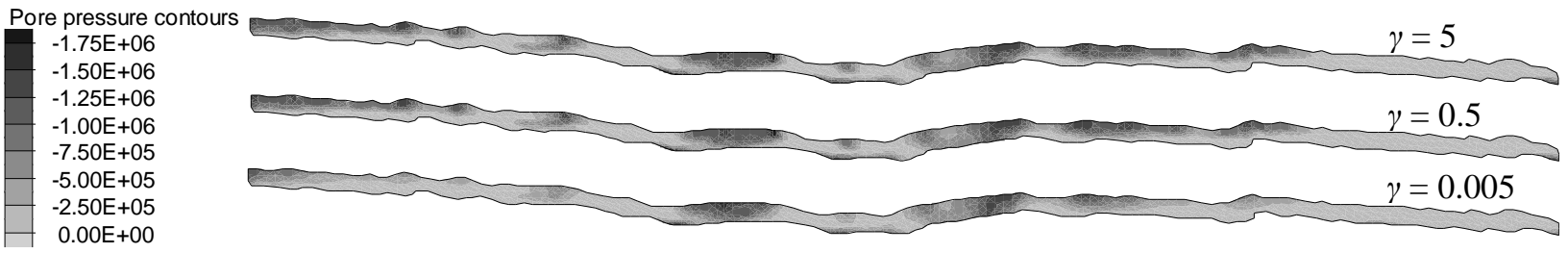

Fig. 12. Pore pressure contours at the end of shearing under different physical shear rates
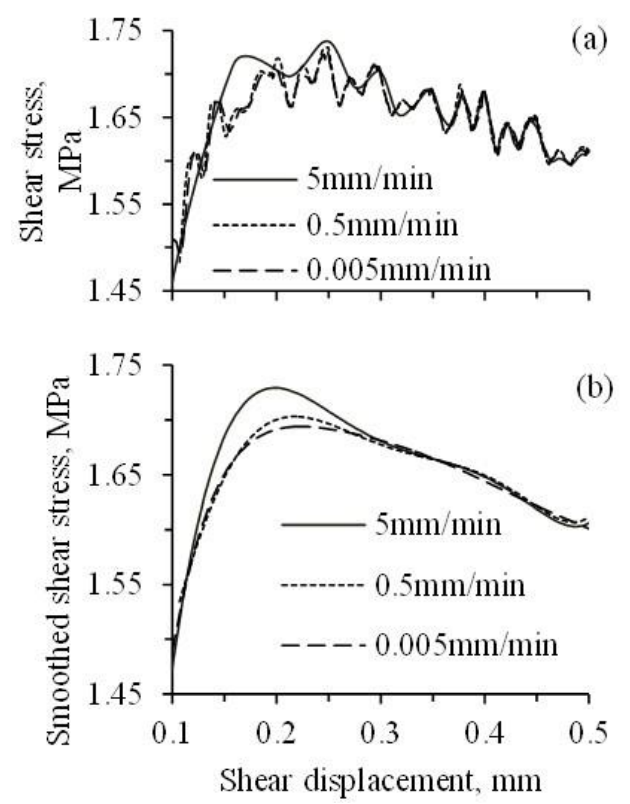

Fig. 13. Shear stress curves at different physical shear rates: (a) zoomed curves; (b) smoothed curves

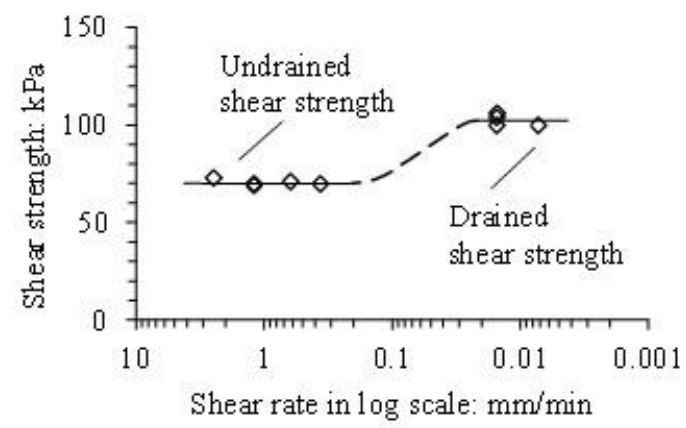

Fig. 14. Shear strength curve of infilled joints obtained in direct shear tests under different shear rates (Data from de Toledo \& de Freitas 1993.) 

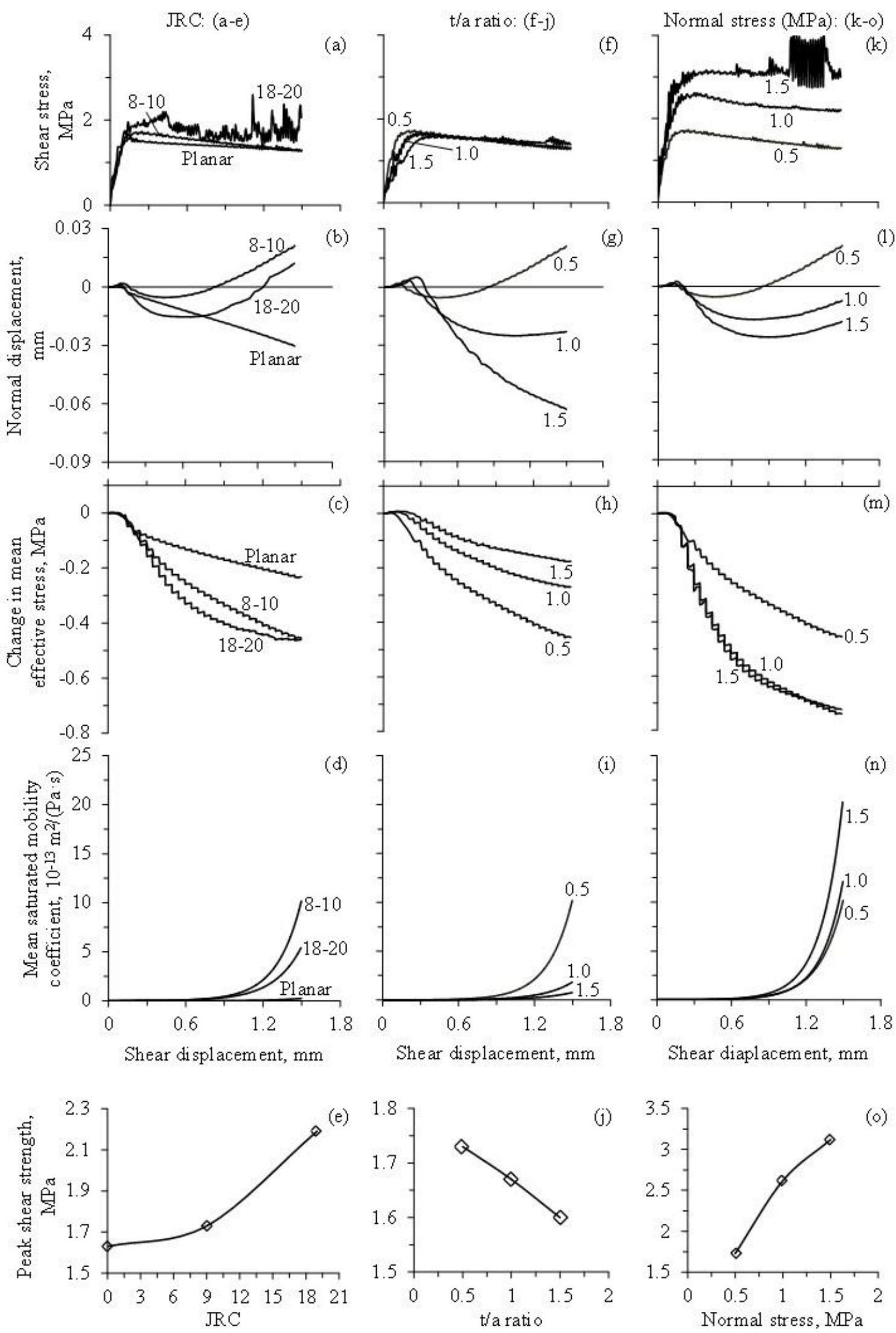

Fig. 15. Shear behaviour of infilled joints under varying $(a-e) J R C,(f-j) t / a$ ratio, and $(k-0)$ normal stress (MPa) 


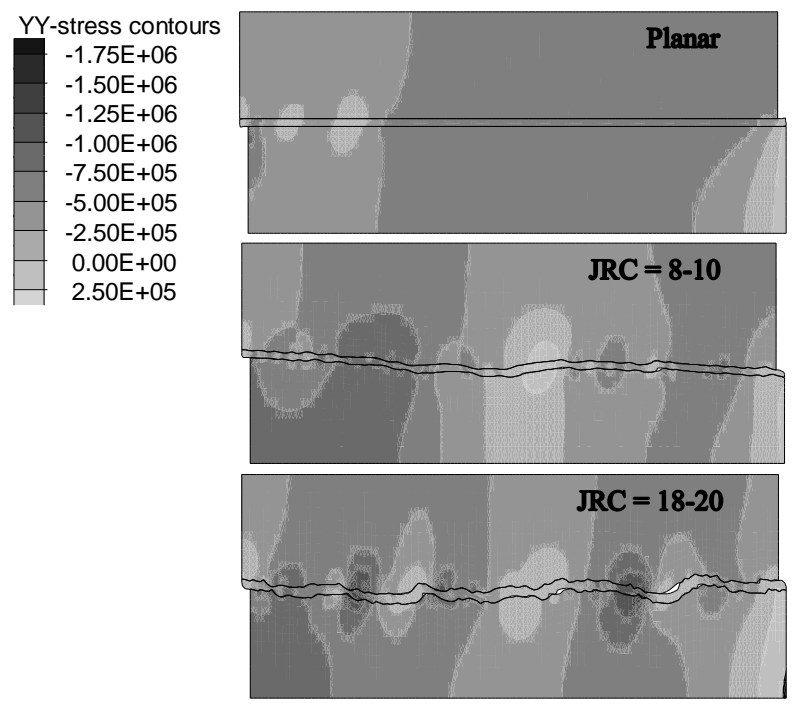

Fig. 16. yy-stress contours at the end of shearing with different JRC values

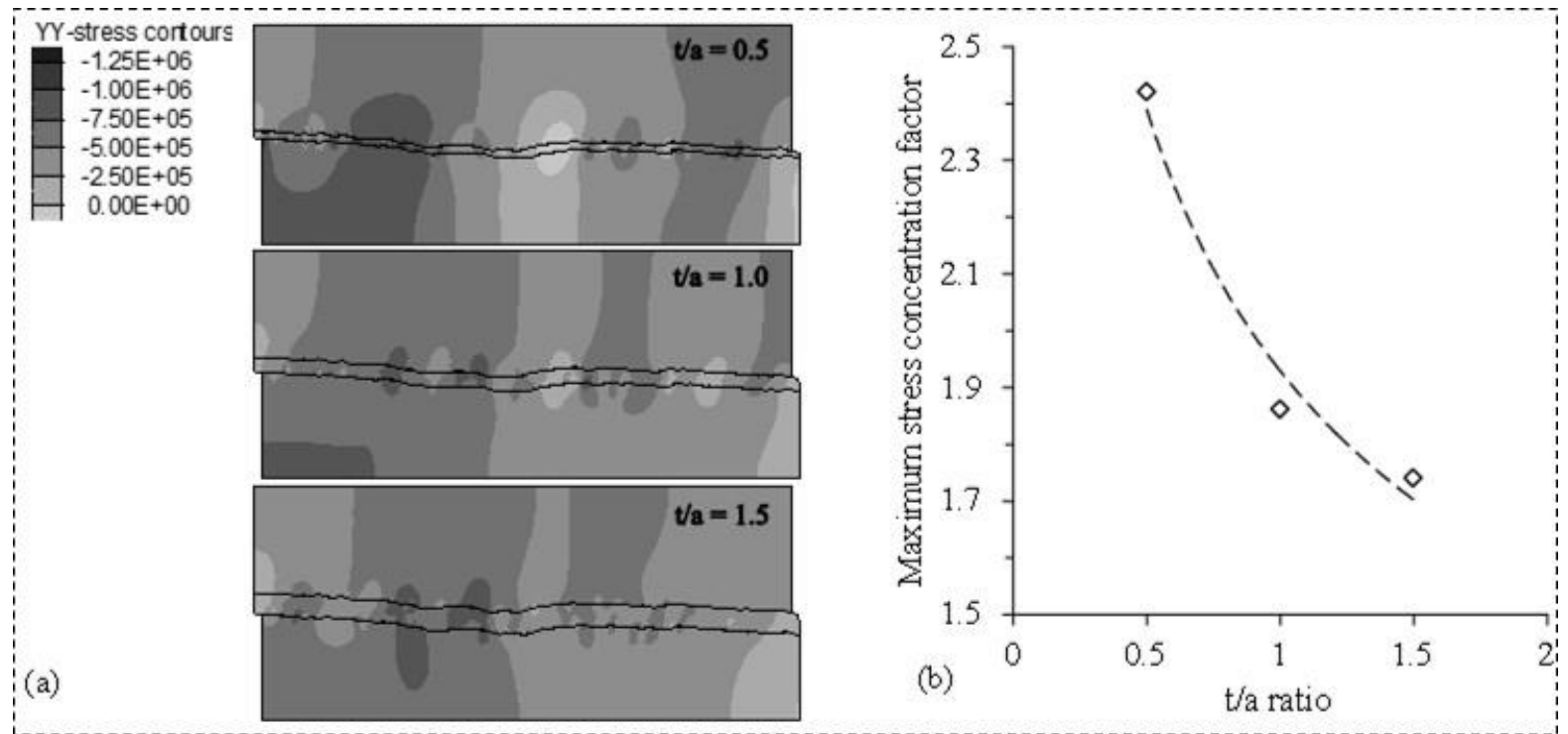

Fig. 17. Vertical stress concentration within the infill layer under different $t / a$ ratio: (a) yy-stress contours; (b) maximum stress concentration factor 
Table 1. Model series for various influencing parameters

\begin{tabular}{|c|c|c|c|c|c|c|c|}
\hline $\begin{array}{l}\text { Series } \\
\text { Number }\end{array}$ & $\begin{array}{c}\text { Porosity } \\
\text { update } \\
\text { Times, } N\end{array}$ & $\begin{array}{l}\text { Applied } \\
\text { Velocity, } v \\
\text { (m/step) }\end{array}$ & $\begin{array}{l}\text { Initial Deg. of } \\
\text { Saturation, } S_{\mathrm{r} 0} \\
(\%)\end{array}$ & $\begin{array}{c}\text { Physical } \\
\text { Shear Rate, } \gamma \\
(\mathrm{mm} / \mathrm{min})\end{array}$ & $\mathrm{JRC}$ & $\begin{array}{l}t / a \text { or infill } \\
\text { thickness } t\end{array}$ & $\begin{array}{l}\text { Normal } \\
\text { Stress, } \sigma_{\mathrm{n}} \\
(\mathrm{MPa})\end{array}$ \\
\hline 1 & 0 & $1 \times 10^{-8}$ & 50 & 0.5 & $8-10$ & 0.5 & 0.5 \\
\hline 2 & 15 & $1 \times 10^{-8}$ & 50 & 0.5 & $8-10$ & 0.5 & 0.5 \\
\hline 3 & 30 & $1 \times 10^{-8}$ & 50 & 0.5 & 8-10 & 0.5 & 0.5 \\
\hline 4 & 60 & $1 \times 10^{-8}$ & 50 & 0.5 & $8-10$ & 0.5 & 0.5 \\
\hline 5 & 30 & $1 \times 10^{-6}$ & 50 & 0.5 & $8-10$ & 0.5 & 0.5 \\
\hline 6 & 30 & $1 \times 10^{-7}$ & 50 & 0.5 & $8-10$ & 0.5 & 0.5 \\
\hline 7 & 30 & $1 \times 10^{-9}$ & 50 & 0.5 & $8-10$ & 0.5 & 0.5 \\
\hline 8 & 30 & $1 \times 10^{-8}$ & 60 & 0.5 & $8-10$ & 0.5 & 0.5 \\
\hline 9 & 30 & $1 \times 10^{-8}$ & 99 & 0.5 & $8-10$ & 0.5 & 0.5 \\
\hline 10 & 30 & $1 \times 10^{-8}$ & 50 & 5 & $8-10$ & 0.5 & 0.5 \\
\hline 11 & 30 & $1 \times 10^{-8}$ & 50 & 0.005 & $8-10$ & 0.5 & 0.5 \\
\hline 12 & 30 & $1 \times 10^{-8}$ & 50 & 0.5 & 0 (planar) & $t=1.47 \mathrm{~mm}$ & 0.5 \\
\hline 13 & 30 & $1 \times 10^{-8}$ & 50 & 0.5 & $18-20$ & 0.5 & 0.5 \\
\hline 14 & 30 & $1 \times 10^{-8}$ & 50 & 0.5 & $8-10$ & 1.0 & 0.5 \\
\hline 15 & 30 & $1 \times 10^{-8}$ & 50 & 0.5 & $8-10$ & 1.5 & 0.5 \\
\hline 16 & 30 & $1 \times 10^{-8}$ & 50 & 0.5 & $8-10$ & 0.5 & 1.0 \\
\hline 17 & 30 & $1 \times 10^{-8}$ & 50 & 0.5 & $8-10$ & 0.5 & 1.5 \\
\hline
\end{tabular}

Note: bold terms in each column represent the selected changing levels of the corresponding parameter in that column.

Table 2. Soil properties of the infill layer

\begin{tabular}{|l|c|}
\hline Property & Value \\
\hline Soil & Speswhite kaolin \\
\hline USCS classification & $\mathrm{CH}$ \\
\hline Silt $(0.074-0.002 \mathrm{~mm})(\%)$ & 20 \\
\hline Clay $(<0.002 \mathrm{~mm})(\%)$ & 80 \\
\hline Liquid limit, $L L(\%)$ & 64 \\
\hline Plastic limit, $P L(\%)$ & 32 \\
\hline$P I(\%)$ & 32 \\
\hline Specific gravity, $G_{\mathrm{s}}$ & 2.6 \\
\hline
\end{tabular}

Table 3. Infilled joint specimen properties required in FLAC

\begin{tabular}{|l|c|c|c|}
\hline Property & Rock (hydrostone) & Infill material & Rock-infill interface \\
\hline Constitutive model & isotropic elastic & M-C model & - \\
\hline Dry density $\left(\mathrm{kg} / \mathrm{m}^{3}\right)$ & 2500 & 1500 & - \\
\hline Elastic drained bulk modulus, $K(\mathrm{~Pa})$ & $10.65 \times 10^{9}$ & $7.8 \times 10^{6}$ & \\
\hline Elastic shear modulus, $G(\mathrm{~Pa})$ & $4.36 \times 10^{9}$ & $5.8 \times 10^{6}$ & \\
\hline Poisson's ratio & 0.32 & 0.2 & - \\
\hline Drained cohesion, $c(\mathrm{~Pa})$ & - & $10 \times 10^{3}$ & $10 \times 10^{3}$ \\
\hline Drained friction angle, $\phi$ & - & 17 & 20 \\
\hline Dilation angle & - & 0 & 0 \\
\hline Tension limit $(\mathrm{Pa})$ & - & 0 & 0 \\
\hline Initial porosity, $n_{0}$ & 0.544 & 0.544 & - \\
\hline Normal stiffness, $k_{\mathrm{n}}(\mathrm{Pa} / \mathrm{m})$ & - & - & $3.1 \times 10^{10}$ \\
\hline Shear stiffness, $k_{\mathrm{s}}(\mathrm{Pa} / \mathrm{m})$ & - & - & $3.1 \times 10^{10}$ \\
\hline
\end{tabular}

Table 4. Permeability, water retention parameters and fluid properties 


\begin{tabular}{|l|c|}
\hline Property & Values \\
\hline Initial saturated mobility coefficient $\left(\mathrm{m}^{2} /(\mathrm{Pa} \cdot \mathrm{s})\right)$ & $2 \times 10^{-15}$ \\
\hline Van Genuchten parameter, $a$ & 0.2275 \\
\hline Van Genuchten parameter, $b$ & 0.5 \\
\hline Van Genuchten parameter, $c$ & 0.5 \\
\hline Gallipoli parameter, $\varphi$ & 0.004621 \\
\hline Gallipoli parameter, $\psi$ & 4.117 \\
\hline Fluid modulus for water, $K_{\mathrm{w}}(\mathrm{Pa})$ & $2 \times 10^{9}$ \\
\hline Fluid modulus for air, $K_{\mathrm{g}}(\mathrm{Pa})$ & 1 \\
\hline Residual degree of water saturation, $S_{\text {res }}$ & 0 \\
\hline Undrained coefficient, $\beta$ & 1 \\
\hline Viscosity ratio, $\mu_{\mathrm{w}} / \mu_{\mathrm{g}}$ & 1 \\
\hline
\end{tabular}

Table 5. General trends of some important variables during joint shear regardless of changing conditions

\begin{tabular}{|l|l|l|}
\hline Variable & \multicolumn{1}{|c|}{ First stage } & \multicolumn{1}{c|}{ Second stage } \\
\hline Shear stress & $\begin{array}{l}\text { Raises linearly (elastic stage) then keeps increasing } \\
\text { to a peak with decaying slope }\end{array}$ & $\begin{array}{l}\text { Reduces to a residual state or remains } \\
\text { stable }\end{array}$ \\
\hline Dilation & Contracts noticeably after initial slight dilation & Dilates or keeps contracting \\
\hline Mean effective stress & Accelerated drop after initial small increase & Reduces continually with decaying slope \\
\hline Mean saturated mobility coefficient & Increases slowly; almost holds steady & Increases exponentially \\
\hline
\end{tabular}

Table 6. Relationships between each infilled joint parameter and some important variables

\begin{tabular}{|c|c|c|c|c|c|}
\hline \multirow{2}{*}{ Variable } & \multicolumn{5}{|c|}{ Increase in: } \\
\hline & $S_{\mathrm{r} 0}$ & $\gamma$ & JRC & $t / a$ & $\sigma_{\mathrm{n}}$ \\
\hline Peak shear strength & Significant decrease & Slight increase & Dramatic increase & Noticeable decrease & Dramatic increase \\
\hline Shear stress & Decrease & Increase & Increase & Decrease & Increase \\
\hline Dilation & $\begin{array}{c}\text { Dilation comes earlier } \\
\text { during shear }\end{array}$ & $\begin{array}{l}\text { Larger in later } \\
\text { stage of shear }\end{array}$ & $\begin{array}{l}\text { Dilation occurs except } \\
\text { for planar joints }\end{array}$ & Less dilation & Less dilation \\
\hline Mean effective stress & Less decrease & $\begin{array}{l}\text { Larger in later } \\
\text { stage of shear }\end{array}$ & Decrease & Increase & $\begin{array}{l}\text { Decreases to } \\
\text { steady state }\end{array}$ \\
\hline $\begin{array}{l}\text { Mean saturated } \\
\text { mobility coefficient }\end{array}$ & Increase & $\begin{array}{l}\text { Larger in later } \\
\text { stage of shear }\end{array}$ & Increase & Decrease & Increase \\
\hline
\end{tabular}

